Varma, R.K., Barros, J.A.O., Sena-Cruz, J.M. (2009) Numerical model for CFRP confined concrete elements subject to monotonic and cyclic loadings, Composites Part B, 40(8): 766-775.

\title{
NUMERICAL MODEL FOR CFRP CONFINED CONCRETE ELEMENTS SUBJECT TO MONOTONIC AND CYCLIC LOADINGS
}

\author{
By Rajendra K. Varma ${ }^{1}$, Joaquim A. O. Barros ${ }^{2}$, José M. Sena-Cruz ${ }^{3}$ \\ ${ }^{1}$ PhD Student, Dept. of Civil Engineering, Univ. of Minho, Azurém, 4800-058 Guimarães, Portugal. \\ E-mail: rajendra@civil.uminho.pt \\ ${ }^{2}$ Associate Professor, Dept. of Civil Engineering, Univ. of Minho, Azurém, 4800-058 Guimarães, Portugal. \\ E-mail: barros@ civil.uminho.pt Tel: +351253510210 Fax: +351253510217 Corresponding Author \\ ${ }^{3}$ Assistant Professor, Dept. of Civil Engineering, Univ. of Minho, Azurém, 4800-058 Guimarães, Portugal. \\ E-mail: jsena@ civil.uminho.pt
}

\section{Abstract}

Uniaxial cyclic and monotonic compression tests were carried out on partially and fully wrapped concrete cylinders with Carbon Fibre Reinforced Polymer (CFRP) wet lay-up sheets. The influence of the concrete compressive strength, CFRP stiffness, geometric confinement arrangement and loading type on the compressive behaviour of reinforced concrete column elements of circular cross section up to their failure was assessed. A uniaxial stress-strain constitutive model is proposed, and the results obtained from the experimental tests were used to calibrate some of the parameters of this model, and to appraise the model performance. This model allows the simulation of reinforced concrete members by using Timoshenko one-dimensional elements, in the context of the finite element method (fibre model). Good agreement was obtained between numerical simulations and experimental results for both monotonic and cyclic loading tests.

Keywords: Carbon Fibre; Computational modelling; Finite element analysis (FEA); Cyclic constitutive model 
Varma, R.K., Barros, J.A.O., Sena-Cruz, J.M. (2009) Numerical model for CFRP confined concrete elements subject to monotonic and cyclic loadings, Composites Part B, 40(8): 766-775.

\section{Introduction}

In the last decade the use of Carbon Fibre Reinforced Polymer (CFRP) materials has significantly increased, being the confinement of concrete columns one of the most promising applications of this composite. In fact, wet lay-up CFRP sheets, arranged in order to constitute partial or full wrapping confinement systems, can be used to significantly increase the load carrying and energy dissipation capacities of circular concrete columns. The magnitude of these structural improvements depends on several parameters, such as: concrete strength; CFRP percentage; geometric confinement arrangement; column aspect ratio; arrangement and percentage of existing steel reinforcement. The remarkable properties of CFRP sheets, like the low weight, high strength and easy installation, make them highly suitable for the confinement of reinforced concrete (RC) columns. However, the elastic behaviour up to the abrupt rupture of these materials should be taken into account, due to the brittle failure mode and its consequence in terms of the ductility performance of CFRP confined columns.

Several experimental studies [1-6] have been carried out to understand the role of CFRP sheets as a confining material, and to derive enough data that can be used for the development and appraisal of constitutive models. Most of the studies have been limited to the monotonic compressive loading, except few ones [7-9] that have investigated the influence of the cyclic loading on the behaviour of FRP confined concrete elements. The CFRP confinement effectiveness on plain concrete cylinder specimens of small dimensions was investigated by Shao et al. [8] and Lam et al. [9], while Ferreira [10] explored the CFRP confinement effectiveness on larger column elements of concrete strength range representative of the concrete structures requiring strengthening intervention.

In past, some researchers ([1] and [11]) modified the uniaxial stress-strain model proposed by Mander et al. [12] for concrete columns confined with steel hoops, to take into account the assumption of constant confining pressure exerted by the steel hoops, which can not be assumed for FRP materials due to the linear elastic behaviour of these composites up to their brittle failure. In the present work, a new model is proposed to simulate the behaviour of CFRP fully and partially confined RC columns subject to cyclic loading. The considered monotonic stress-strain relationship (envelope of the cyclic curve, as proved in a previous work - Ferreira [10]) is supported on the principles proposed by Harajli et al. [13], while the hysteretic stress-strain cycles were derived using an approach similar to the analytical model of Chang and Mander [14], and evaluating relevant parameters of this model from the available experimental data. 
Varma, R.K., Barros, J.A.O., Sena-Cruz, J.M. (2009) Numerical model for CFRP confined concrete elements subject to monotonic and cyclic loadings, Composites Part B, 40(8): 766-775.

With the purpose of developing a constitutive model for CFRP confined circular concrete columns subject to monotonic and cyclic loadings, the present work starts with the presentation of the relevant results of the experimental program carried out at the University of Minho. The constitutive model is then described and the values of crucial parameters are determined from the experimental results. Finally, the performance of the developed constitutive model, which was implemented into a FEM-based software for the material nonlinear analysis of concrete structures, was appraised using the experimental results.

\section{Experimental research}

\subsection{Specimen nomenclature and properties}

The experimental program deals with monotonic and cyclic axial compression tests on concrete cylinders of $200 \mathrm{~mm}$ diameter (D) and $600 \mathrm{~mm}$ height (H), divided in the G1, G2 and G3 groups, whose characteristics are indicated in Tables 1 to 3 , respectively. In these tables $f_{c o, U P C}$ and $\varepsilon_{c o, U P C}$ are the concrete compressive strength of unconfined plain concrete (UPC here after) specimens and its corresponding axial strain, respectively. A total of $54 \mathrm{RC}$ specimens were tested to evaluate the effectiveness of full and distinct partial confinement CFRP arrangements. The experimental program was planned to assess the influence of the following parameters on the concrete confinement effectiveness: concrete strength class; stiffness and percentage of CFRP; concrete free space between CFRP strips; number of CFRP layers per each strip. The influence of the longitudinal and transversal steel reinforcement arrangements in terms of compressive strength, energy dissipation and ultimate deformability was analyzed in a previous publication [6], and, as expected, their relatively low contribution was in the range indicated by available research on this topic.

Each specimen is designated as $\mathbf{W} i \mathbf{S} j \mathbf{L} k \mathbf{F} l_{-} c / m$, where $\mathbf{W} i$ represents the strip width in $\mathrm{mm}, \mathbf{S} j$ is the number of strips along the height of the cylinder, $\mathbf{L} k$ represents the number of CFRP layers per each strip, and $\mathbf{F} l$ represents the diameter of the longitudinal steel bars, in $\mathrm{mm}$. To distinguish cyclic from monotonic tests, the $c$ character was attributed to the cyclic tests, while the $m$ letter was used to designate monotonic tests. Fig. 1 represents the characteristics of the typical specimens, where $s_{s}$ is the spacing between steel hoops and $s_{f}$ is the clear spacing between consecutive CFRP strips (for full wrapping $s_{f}=0$ ). The diameter of the steel hoops $\left(d_{s t}\right.$, see Fig. 1) is $160 \mathrm{~mm}$, with a concrete cover of $20 \mathrm{~mm}$, while the diameter of its cross-section is $6 \mathrm{~mm}$. All the specimens were reinforced with four longitudinal bars $(4 \Phi 8$ 
Varma, R.K., Barros, J.A.O., Sena-Cruz, J.M. (2009) Numerical model for CFRP confined concrete elements subject to monotonic and cyclic loadings, Composites Part B, 40(8): 766-775.

in some series and $4 \Phi 10$ in the other series, see Fig. 1) equally spaced at a distance of $80 \mathrm{~mm}$ from longitudinal axis of specimen.

In Tables 1 to $3 f_{c u}$ and $\varepsilon_{c u}$ (see Fig. 4) are the ultimate concrete compressive strength of CFRP confined concrete specimen and its corresponding axial strain, respectively, $t_{f}$ is the thickness of the CFRP sheet, and $\rho_{f}$ is the CFRP volumetric ratio given by:

$$
\rho_{f}=4 \frac{W L S t_{f}}{D H}
$$

where the values of $W, L$ and $S$ can be derived from the specimen designation, as described above. CFRP confined and UPC cylinders of each series were prepared from the same concrete batch. Two cylinders were tested for each confinement arrangement, as well as for UPC. More details about the preparation of the specimens can be found elsewhere [10].

\subsection{Material properties}

Two types of CFRP sheets were used in the experimental program, one with the trade name of CF120 (200 g/m $\mathrm{m}^{2}$ of fibres) and the other designated as CF130 (300 g/m² of fibres). The mechanical properties of the sheets were determined by experimental tests on five samples for each type of sheet. The tests were conducted according to ISO recommendations [15]. The CF130 sheets had a thickness $\left(t_{f}\right)$ of $0.176 \mathrm{~mm}$, an elasticity modulus $\left(E_{f}\right)$, an ultimate strain $\left(\varepsilon_{f u}\right)$ and a tensile strength $\left(f_{f u}\right)$ in the fibre direction of $230 \mathrm{GPa}, 1.33 \%$ and $3070 \mathrm{MPa}$, respectively. In the tests with $\mathrm{CF} 120$ sheets the following values were obtained: $t_{f}=0.113 \mathrm{~mm} ; E_{f}=232 \mathrm{GPa} ; \varepsilon_{f u}=1.52 \% ; f_{f u}=3535 \mathrm{MPa}$. The values of the mechanical properties of longitudinal and transversal steel bars are included in Table 4 . In this table, $f_{s y}, f_{s h}$ and $f_{s u}$ represent the tensile yield stress, hardening stress and tensile strength, respectively, $\varepsilon_{s h}$ and $\varepsilon_{s u}$ are the steel strains corresponding to $f_{s h}$ and $f_{s u}$, and $E_{s}$ and $E_{s h}$ are the elasticity modulus and the tangent modulus at the initial of the hardening phase, respectively.

\subsection{Test procedure}

Three Linear Variable Displacement Transducers (LVDTs) were placed at $120^{\circ}$ from each other around the cylindrical specimen to measure the axial displacements. The specimens subject to cyclic compressive loading were tested under force control at a load rate of $15 \mathrm{kN} / \mathrm{s}$. The cyclic loading started at a load level 
Varma, R.K., Barros, J.A.O., Sena-Cruz, J.M. (2009) Numerical model for CFRP confined concrete elements subject to monotonic and cyclic loadings, Composites Part B, 40(8): 766-775.

of $1000 \mathrm{kN}$ and ended at $2000 \mathrm{kN}$, with increments of $250 \mathrm{kN}$. Each load level was composed by three repeated cycles with the same amplitude. The unloaded branches were reversed to reloading at a load level of $30 \mathrm{kN}$. After the last cycle, the test was conducted in displacement control, at a displacement rate of $5 \mu \mathrm{m} / \mathrm{s}$, up to the rupture of the specimen. The monotonic tests were performed under displacement control at a displacement rate of $5 \mu \mathrm{m} / \mathrm{s}$.

\subsection{Experimental results}

Figs 2(a) and (b) illustrate the typical correlations between $f_{c u} / f_{c o, U P C}$ and $\rho_{f}$, and between $\varepsilon_{c u} / \varepsilon_{c o, U P C}$ and $\rho_{f}$, respectively. Tables 1 to 3 and Fig. 2(a) reveal that the load carrying capacity of the specimens increased with $\rho_{f}$, regardless the type of confinement arrangement. Since for the same $\rho_{f}$, partial confinement arrangements require smaller area of concrete treatment for the application of the CFRP material than in the case of full confinement, economic benefits can result from the option for the former confinement strategies. Fig. 2(b) also shows a tendency of $\varepsilon_{c u} / \varepsilon_{c o, U P C}$ to increase with $\rho_{f}$. However, when compared to the trend observed in the $f_{c u} / f_{c o, U P C}-\rho_{f}$, a high dispersion was registered. Due to the accumulation of the concrete compressive plastic strain, mainly in between CFRP strips, Fig. 2(b) shows that, for similar $\rho_{f}$, partial confinement arrangements presented larger $\varepsilon_{c u} / \varepsilon_{c o, U P C}$ ratio than full-wrapping configurations.

Typical stress-strain curves of monotonic tests and cyclic tests are compared in Fig. 3 (see also Table 3). The stress-strain curves of all tested specimens are available in Ferreira [10]. From the analysis of Fig. 3 it is observed that a good fit exist between the envelope of the cyclic stress-strain curve and the stressstrain curve of the corresponding monotonic test. The envelope curve can be idealized as composed by three branches. The first one, of an almost linear trend with a slope that depends basically on the RC properties, is followed by a transition branch of pronounced non-linearity, which ends in another almost linear branch of a slope that depends, mainly, on the CFRP confinement properties. This slope has a tendency to increase with $\rho_{f}$. In each series of load cycles, the concrete axial strain increased from the first to the third cycle. This increase can be justified by the concrete dilation, mainly at the zones in-between CFRP strips. Due to the increase of tensile strains in the CFRP in subsequent load cycles of each series of load cycles, an increase of confinement pressure is introduced into concrete by the CFRP system, hence the reloading branch of the last cycle of each series of load cycles (the returning to the monotonic phase) 
Varma, R.K., Barros, J.A.O., Sena-Cruz, J.M. (2009) Numerical model for CFRP confined concrete elements subject to monotonic and cyclic loadings, Composites Part B, 40(8): 766-775.

has exceeded the load carrying capacity of the homologous monotonic specimen. As expected, this behaviour was more pronounced in the full-wrapped specimens. It is also verified that the unloading branch is eminently nonlinear, while the reloading branch is composed by nonlinear segments of reduced amplitude at its extremities, connected by a linear part.

Considering the shape of the unloading and reloading branches, it is not possible to adopt a polynomial equation for their simulation. Therefore, transition type equations (described later) are adopted to provide the required curvature to the nonlinear parts of the unloading and reloading branches. Another prominent feature, which is visible in Fig. 3, is the asymptotic nature of the reloading branch in the vicinity of the envelope curve. Assuming that Fig. 4 represents the fundamental features of CFRP confined concrete and, comparing Fig. 3 with Fig. 5, it is observed that the non-linearity of the reloading branch is more pronounced near the envelope curve than in the starting part of this branch (at point $\mathrm{N}$ in Fig. 4). In consequence, two transition type equations are required to model a reloading branch up to the envelope curve.

The unloading secant stiffness ( $E_{c \sec u}$ ), see Fig. 4, is neither equal to the initial Young's modulus $\left(E_{c i}\right)$ nor to the reloading secant stiffness $\left(E_{c \sec r}\right)$. The $E_{c \sec u}$ is always greater than the corresponding $E_{c \sec r}$. This implies that in a full unloading-reloading cycle, the reloading strain ( $\varepsilon_{c r e}$, point M in Fig. 4) on the envelope is always greater than the unloading strain on the envelope ( $\varepsilon_{\text {cun }}$, point L in Fig. 4).

The plastic strain, $\varepsilon_{c p l}$, is one of the most crucial features of the cyclic tests. Shao et al. [8] considered that during an hysteretic phase, the plastic strain is kept constant, regardless of being a full or a partial unloading. However, Fig. 2 does not support this assumption.

In the successive series of load cycles, a tendency for the decrease in stiffness of unloading and reloading branches was observed in all tested specimens. The decrease in the stiffness of these branches diminished with the increase of the specimen axial deformation. The stiffness of the unloading and reloading branches seems to approach a constant value (residual stiffness) with the increase of the specimen axial deformation.

\section{Constitutive model for CFRP confined concrete elements}

\subsection{Compression envelope curve}

The monotonic compression stress-strain envelope curve is composed of a linear branch (indicated as zone I in Fig. 4), followed by a transition nonlinear branch (zone II) and ends with another nonlinear 
Varma, R.K., Barros, J.A.O., Sena-Cruz, J.M. (2009) Numerical model for CFRP confined concrete elements subject to monotonic and cyclic loadings, Composites Part B, 40(8): 766-775.

branch (zone III). In zone I (branch $\overline{O P}$ ) the CFRP has marginal influence, while zone III (branch $\overline{Q u}$ ) is significantly influenced by the effective lateral pressure provided by the CRFP confinement arrangements. Zone II (branch $\overline{P Q}$ ) is clearly nonlinear, connecting the branches that simulate the zones I and III. This nonlinearity is a result of the concrete nonlinear behaviour due to its crack initiation (near point $\mathrm{P}$ in Fig. 4) and propagation up to a strain level corresponding to the initiation of the UPC softening phase (point Q in Fig. 4). According to this approach, the zone I (for $0 \leq \varepsilon_{c} \leq \varepsilon_{c P}$ ) is simulated using the following eqs.:

\begin{tabular}{|l|c|}
\hline$f_{c}\left(\varepsilon_{c}\right)=E_{c i} \varepsilon_{c}$ & $(2 \mathrm{a})$ \\
\hline$E_{c}\left(\varepsilon_{c}\right)=E_{c i}$ & $(2 \mathrm{~b})$ \\
\hline$\varepsilon_{c P}=\beta \varepsilon_{c o, U P C}$ & (2b) \\
\hline
\end{tabular}

where $E_{c i}$ is the concrete initial Young's modulus calculated according to the recommendations of CEBFIB Model Code [16] for UPC, or evaluated experimentally. The parameter $\beta$ represents the percentage of $\varepsilon_{c o, U P C}$ up to which UPC has linear and elastic behaviour. The available experimental research [10] shows that $\beta$ has a tendency to increase with the concrete compressive strength. For the concrete used in the present work, a $\beta=0.4$ was assumed. The transition curve that simulates the zone II, starts from an already well-known point $\left(\varepsilon_{c a}, f_{c a}\right)$ (a subscript $a$ is used to designate starting point) with corresponding slope $\left(E_{c a}\right)$, and ends at a target point $\left(\varepsilon_{c b}, f_{c b}\right)$ (a subscript $b$ is used to designate ending point) with a slope $\left(E_{c b}\right)$. In Fig. 4 the start and target points of zone II correspond to points $\mathrm{P}$ and Q, respectively. The transition curve (for $\varepsilon_{c P} \leq \varepsilon_{c} \leq \varepsilon_{c Q}$ ) is simulated using the following eqs.:

\begin{tabular}{|l|l|}
\hline$f_{c}\left(\varepsilon_{c}\right)=f_{c a}+\left(\varepsilon_{c}-\varepsilon_{c a}\right)\left[E_{c a}+A\left|\varepsilon_{c}-\varepsilon_{c a}\right|^{R}\right]$ \\
$E_{c}\left(\varepsilon_{c}\right)=E_{c a}+A(R+1)\left|\varepsilon_{c}-\varepsilon_{c a}\right|^{R}$ & (3a) \\
\hline$R=\frac{E_{c a}-E_{c s e c}}{E_{c s e c}-E_{c b}}$ and $A=\frac{E_{c s e c}-E_{c a}}{\left|\varepsilon_{c b}-\varepsilon_{c a}\right|^{R}}$ & (3c) \\
\hline$E_{\mathrm{csec}}=\frac{f_{c b}-f_{c a}}{\varepsilon_{c b}-\varepsilon_{c a}}$ & (3d) \\
\hline
\end{tabular}

In Table $5 E_{c P}$ and $f_{c P}$ represent the tangential modulus and the stress calculated at $\varepsilon_{c P}$ from Eq. 2 (zone I), and $E_{c Q}$ and $f_{c Q}$ represent the tangential modulus and the stress calculated at $\varepsilon_{c Q}$ on zone III, according to the procedures to be described in next steps. In the present approach it is adopted that: 
Varma, R.K., Barros, J.A.O., Sena-Cruz, J.M. (2009) Numerical model for CFRP confined concrete elements subject to monotonic and cyclic loadings, Composites Part B, 40(8): 766-775.

$$
\varepsilon_{c Q}=\gamma \mathcal{E}_{c o, U P C}
$$

From the available research [10] it seems reasonable to assume that the lateral confining pressure provided by CFRP systems becomes significant (a maximum tensile strain in the CFRP of about $2 \%$ ) at an axial compressive strain around $1.5 \varepsilon_{c o, U P C}$, resulting a value of 1.5 for the $\gamma$ parameter.

If $\varepsilon_{c u}$ represents the ultimate axial compressive strain of CFRP confined concrete, considering the high dispersion for the $\varepsilon_{c u} / \varepsilon_{c o, U P C}$ values, an upper bound for the $\varepsilon_{c u} / \varepsilon_{c o, U P C}-\rho_{\mathrm{f}}$ relationship was considered, resulting:

$$
\varepsilon_{c u}=\left(800 \rho_{f}+6\right) \varepsilon_{c o, U P C} \text { for } 0.0025 \leq \rho_{f} \leq 0.0176
$$

The stress-strain relationship for zone III $\left(\varepsilon_{c Q} \leq \varepsilon_{c} \leq \varepsilon_{c u}\right)$ is defined from the following eqs. (Harajli et al. [13]):

\begin{tabular}{|l|l|}
\hline$f_{c}=f_{c o, U P C}+k_{1} f_{l}$ & (6a) \\
\hline $\mathcal{E}_{c}=\varepsilon_{c o, U P C}\left[1+k_{2}\left(\frac{f_{c}}{f_{c o, U P C}}-1\right)\right]$ & (6b) \\
\hline$f_{l}=f_{f l}+f_{s l} \frac{A_{c c}}{A_{g}}$ & (6c) \\
\hline
\end{tabular}

where $f_{l}$ is the effective lateral confinement pressure, $k_{l}$ and $k_{2}$ are confinement effectiveness coefficients derived from the experimental results, $A_{c c}$ is the area of concrete core confined by steel hoops, measured from the centre line of the steel hoop, and $A_{g}$ is the area of the specimen cross section. In Eq. (6c) $f_{f l}$ and $f_{s l}$ represent the effective lateral confining pressure exerted by CFRP and steel hoops, respectively, and they can be determined from the following eqs.:

$$
\begin{aligned}
& f_{f l}=\frac{\alpha_{f e} \alpha_{f v} \rho_{f} E_{f}}{2} \varepsilon_{f} \\
& f_{s l}=\frac{\alpha_{s e} \alpha_{s v} \rho_{s t}}{2} f_{s y t}
\end{aligned}
$$

where $\varepsilon_{f}$ is the lateral strain in CFRP confinement strips, $\rho_{s t}$ is the volumetric ratio of steel hoops (Mander et al. [12]), $f_{s y t}$ is the yield stress of steel hoops, $\alpha_{f e}$ and $\alpha_{f v}$ are the coefficients that account for the effectiveness of the FRP systems in confining the concrete along the plane of the specimen cross section, and the concrete between FRP strips, respectively [12]. The coefficients $\alpha_{s e}$ and $\alpha_{s v}$ account for the effectiveness of the steel hoops in confining the concrete along the plane of the specimen cross 
Varma, R.K., Barros, J.A.O., Sena-Cruz, J.M. (2009) Numerical model for CFRP confined concrete elements subject to monotonic and cyclic loadings, Composites Part B, 40(8): 766-775.

section, and the concrete between steel hoops, respectively [12]. The confinement is considered to be most effective in case of circular columns, where $\alpha_{f e}=\alpha_{s e}=1$, while for the remaining cases these coefficients are evaluated from:

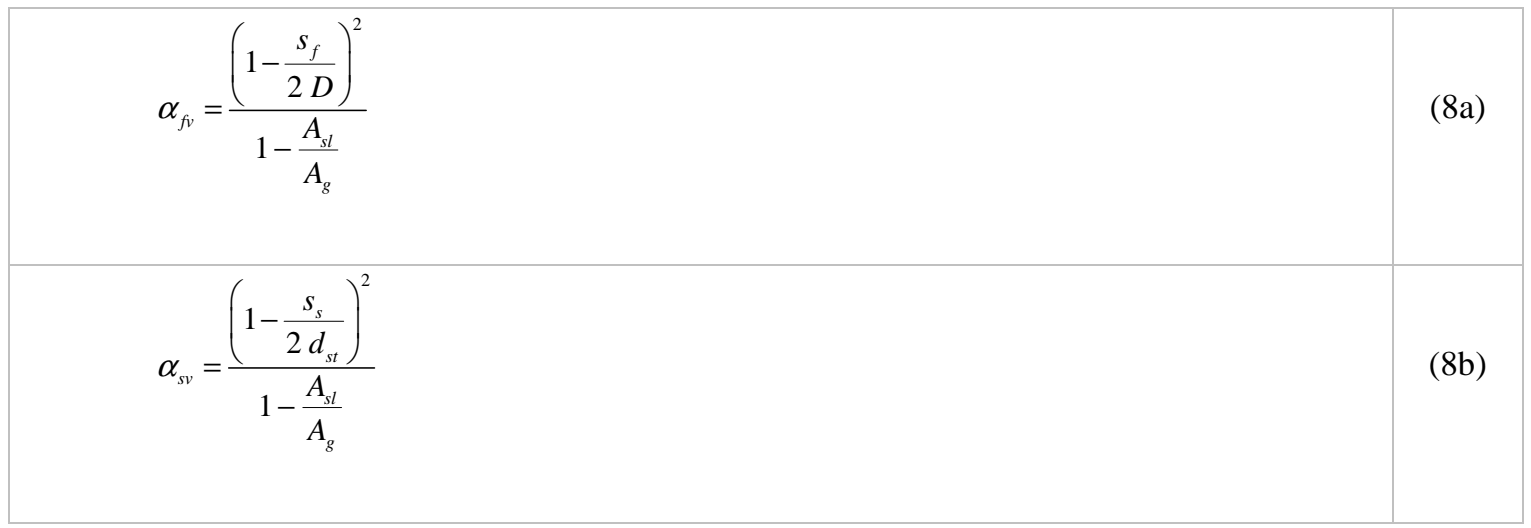

where $A_{s l}$ is the cross section area of the longitudinal steel bars. The relationship between the obtained experimental values of $k_{1}=\left(f_{c}-f_{c o, U P C}\right) / f_{l}$ and $f_{l} / f_{c o, U P C}$ is plotted in Fig. 6 in order to derive an analytical relationship for $k_{1}$. This relationship can be divided in two parts. In fact, Fig. 6 shows that for all specimens $k_{1}$ has a tendency to increase sharply up to a peak value and then decreases exponentially. To represent the influence of the $\rho_{f}$ on the $k_{1}-f_{l} / f_{c o, U P C}$ relationship, markers of a size that increase with the increase of $\rho_{f}$ were used to distinguish the curves of Fig. 6. Comparing Figs. 6(a) and 6(b) it can be observed that, for the same $\rho_{f}, k_{1}$ is as high as larger is the concrete compressive strength. However, for same concrete strength class, $k_{1}$ decreases with the increase of $\rho_{f}$. Based on the results of Fig. 6, the following equations for $k_{1}$ were obtained:

\begin{tabular}{|c|c|}
\hline$k_{1}=m f_{l} / f_{c o, U P C}$ for $f_{l} / f_{c o, U P C} \leq\left(0.12-0.0025 f_{c o, U P C}\right)$ & (9a) \\
\hline$k_{1}=\left(4.4-0.05 f_{c o, U P C}\right)\left(f_{l} / f_{c o, U P C}\right)^{C}$ for $f_{l} / f_{c o, U P C}>\left(0.12-0.0025 f_{c o, U P C}\right)$ & (9b) \\
\hline$C=\frac{\log \left(\frac{A_{k 1}}{4.4-0.05 f_{c o, U P C}}\right)}{\log \left(0.12-0.0025 f_{c o, U P C}\right)} ; m=\frac{A_{k 1}}{\left(0.12-0.0025 f_{c o, U P C}\right)} ; A_{k 1}=\left(0.92 f_{c o, U P C}+0.96\right) \frac{\rho_{f}^{-1 / 3}}{16}$ & (9c) \\
\hline The variation of $k_{2}$ with $\varepsilon_{f}$, derived from the experimental results using Eq. 6(b),
\end{tabular}
$k_{2}=\left(\varepsilon_{c} / \varepsilon_{c o, U P C}-1\right) /\left(f_{c} / f_{c o, U P C}-1\right)$, is represented in Fig. 7 . This figure shows that $k_{2}$ has an exponential increase with the increase of $\varepsilon_{f}$. A tendency for an increase of $k_{2}$ with the decrease of the concrete compressive strength is also apparent. Adopting the strategy of attributing markers of a size proportional 
Varma, R.K., Barros, J.A.O., Sena-Cruz, J.M. (2009) Numerical model for CFRP confined concrete elements subject to monotonic and cyclic loadings, Composites Part B, 40(8): 766-775.

to $\rho_{f}$, this figure shows that, regardless the concrete strength class, $k_{2}$ is as high as low is $\rho_{f}$. Based on the obtained results, the following equations were obtained:

$$
\begin{aligned}
& k_{2}=D_{k_{2}}\left(\varepsilon_{l}\right)^{E_{k_{2}}} \\
& D_{k_{2}}=\frac{\left(7.2-0.05 f_{c o, U P C}\right)}{16 \rho_{f}}, E_{k_{2}}=\left(0.49-0.0025 f_{c o, U P C}\right) \rho_{f}^{-1.3}
\end{aligned}
$$

The concrete tangential modulus, $E_{c}\left(\varepsilon_{c}\right)$, is derived from the chain derivative rule:

$$
E_{c}\left(\varepsilon_{c}\right)=\frac{\partial f_{c}}{\partial \varepsilon_{f}} \frac{\partial \varepsilon_{f}}{\partial \varepsilon_{c}} \text { for } \varepsilon_{c Q} \leq \varepsilon_{c} \leq \varepsilon_{c u} \text { (zone III) }
$$

\subsection{Cyclic hysteretic branches}

The proposed compressive hysteretic scheme is shown in Fig. 5: (i) complete unloading ( $A \rightarrow B$ ); (ii) complete reloading ( $B \rightarrow C \rightarrow D$ ); (iii) partial unloading with complete reloading $\left(A \rightarrow B^{\prime} \rightarrow C^{\prime} \rightarrow D^{\prime}\right.$ ); (iv) complete unloading with partial reloading $\left(A \rightarrow B \rightarrow E^{\prime}\right)$ and; (v) random loading $\left(A \rightarrow B^{\prime} \rightarrow E^{\prime \prime} \rightarrow F^{\prime \prime \prime} \rightarrow E^{\prime \prime \prime} \rightarrow J\right.$ ). Complete unloading here refers to unloading from the envelope curve until zero stress; similarly, complete reloading refers to reloading up to the envelope curve and; partial unloading/reloading refers to all the other possible unloading/reloading cycles that do not fall into the above categories. If $\varepsilon_{\text {cun }}$ is the unloading strain and $f_{\text {cun }}$ its corresponding unloading stress on the envelope curve (Fig. 4), then unloading from this point $\left(\varepsilon_{c u n}, f_{c u n}\right)$, with reversal slope $E_{c u n}\left(=E_{c i}\right.$, point A in Fig. 5), will target the point B ( $\varepsilon_{c p l}, 0$ ), with target slope $E_{c p l}$ (point B in Fig. 5), where $\varepsilon_{c p l}$ is the plastic strain and $E_{c p l}$ is the tangential modulus of unloading curve at $\varepsilon_{c p l}$ that can be determined from Chang and Mander [14]:

$$
E_{\mathrm{cpl}}=0.1 E_{c i} \exp \left(-2\left|\frac{\varepsilon_{c u n}}{\varepsilon_{c o, U P C}}\right|\right)
$$

In the CFRP confined specimens, the degradation of the stiffness of the unloading branches $\left(E_{\text {csecu }}\right)$, during the axial deformation of the specimen, was not so pronounced than in UPC specimens, since CFRP confinement arrangements avoid concrete spalling and the buckling of the longitudinal bars. Normalized unloading secant ( $\left.E_{\text {csecu }} / E_{c i}\right)$ versus normalized unloading strain $\left(\varepsilon_{c u n} / \varepsilon_{c u}\right)$ is plotted in Fig. 
Varma, R.K., Barros, J.A.O., Sena-Cruz, J.M. (2009) Numerical model for CFRP confined concrete elements subject to monotonic and cyclic loadings, Composites Part B, 40(8): 766-775.

8 using the obtained experimental data. The following equation for $E_{\text {csecu }}$ was determined, considering the lower bound of the analyzed data:

$$
\begin{aligned}
& E_{\text {csecu }}=E_{c i} \text { for } 0 \leq \varepsilon_{c u n} \leq 0.032 \varepsilon_{c u} \\
& E_{\text {csecu }}=0.38 E_{c i}\left(\frac{\varepsilon_{c u n}}{\varepsilon_{c u}}\right)^{-0.28} \text { for } \varepsilon_{c u n}>0.032 \varepsilon_{c u}
\end{aligned}
$$

and the plastic strain is determined from (see Fig. 4):

$$
\mathcal{E}_{c p l}=\varepsilon_{c u n}-\frac{f_{c u n}}{E_{c \sec u}}
$$

The equations of the transition curve (Eq. 3(a-d)) are used to join the initial point $A$ and the target point $B$ (see Table 5).

One of the most commonly observed behaviour of confined concrete under a complete cycle is the shift in the strain and stress, represented in Fig. 5 as $\Delta \varepsilon_{c}$ and $\Delta f_{c}$, respectively. Due to the difference in unloading and reloading stiffness, the reloading branch always joins the envelope curve at higher strain compared to the unloading strain on the envelope curve, giving rise to a strain shift, $\Delta \varepsilon_{c}$. A linear dependency between $\Delta \varepsilon_{c}$ and $\varepsilon_{c u n}$, with a regression coefficient of 0.96 , was obtained:

$$
\Delta \varepsilon_{c}=0.19 \varepsilon_{\text {cun }}
$$

Unlike to what happens in unconfined RC column elements subject to cyclic loading, where the shift in stress, $\Delta f_{c}$, depends on the unloading strain of the envelope curve, Fig. 9 shows that in CFRP confined concrete, $\Delta f_{c}$ depends on the latest unloading strain, $\varepsilon_{c u n, g}$. It should be noted that this unloading strain can lie on the envelope curve (the strain at point $\mathrm{A}$ for the $B^{\prime} C E^{\prime \prime}$ reloading branch, in Fig. 5) or on a cyclic reloading branch (the strain at point $E^{\prime \prime}$ for the $F^{\prime \prime \prime} E^{\prime \prime \prime} J$ reloading branch, in Fig. 5). If $f_{\text {cun,g }}$ represents a general unloading stress on either the envelope curve (corresponding to point A in Fig. 5) or on partial reloading branch (corresponding to point $E^{\prime \prime}$ in Fig. 5), and $\varepsilon_{\text {cun }, g}$ its corresponding strain on the respective branch, Fig. 9 represents the relationship between the normalized stress shift $\left(\Delta f_{c} / f_{\text {cun, }}\right)$ and the normalized axial unloading strain $\left(\varepsilon_{\text {can }, g} / \varepsilon_{c u}\right)$, which can be simulated by the following eq.:

$$
\Delta_{c}=0.14 f_{c a n, g}\left(\left|\frac{\varepsilon_{c u n, g}}{\varepsilon_{c u}}\right|\right)^{0.15}
$$


Varma, R.K., Barros, J.A.O., Sena-Cruz, J.M. (2009) Numerical model for CFRP confined concrete elements subject to monotonic and cyclic loadings, Composites Part B, 40(8): 766-775.

The complete reloading curve is defined by three points and two connecting transition curves: the initial $B$, intermediate $C$ and target $D$ points (see Fig. 5). The first transition curve connects point $B\left(\varepsilon_{c p l}, 0\right)$, with a starting slope $E_{c i}$, to an intermediate point $C\left(\varepsilon_{\text {cun }}, f_{\text {cnew }}\right)$ with slope $E_{\text {cnew }}$ (see Table 5), where $f_{\text {cnew }}$ and $E_{\text {cnew }}$ are the stress on the reloading branch and its tangential Young's modulus, respectively, determined from:

$$
\begin{aligned}
& f_{\text {cnew }}=f_{c u m}-\Delta f_{c} \\
& E_{\text {cnew }}=\frac{f_{\text {cnew }}}{\mathcal{E}_{\text {cun }}-\varepsilon_{c p l}}
\end{aligned}
$$

Similarly, the second transition curve connects intermediate point $C\left(\varepsilon_{\text {cun }}, f_{\text {cnew }}\right.$ ), with a slope $E_{\text {cnew }}$, to the return point $D\left(\varepsilon_{c r e}, f_{c r e}\right)$, with a target slope $E_{c r e}$ (see Table 5), where $f_{c r e}$ and $E_{\text {cre }}$ are the stress corresponding to the returning strain $\left(\varepsilon_{c r e}\right)$ and its tangential Young's modulus calculated on the envelope curve, respectively. The parameters required for the complete reloading are calculated from:

\begin{tabular}{|c|c|}
\hline$\varepsilon_{\text {cre }}=\varepsilon_{\text {cum }}+\Delta \varepsilon_{c}$ \\
\hline$E_{\text {cre }}=E_{c}\left(\varepsilon_{c r e}\right)$ \\
\hline$f_{\text {cre }}=f_{c}\left(\varepsilon_{\text {cre }}\right)$
\end{tabular}

After a partial unloading $\left(A \rightarrow B^{\prime}\right)$ a partial or a complete reloading can occur. Irrespective of being a partial or a complete reloading, a modified intermediate point $C^{\prime}\left(\varepsilon_{\text {cun }}, f_{\text {cnew }}^{*}\right)$ and a returning point $D^{\prime}\left(\varepsilon_{c r e}^{*}, f_{c r e}^{*}\right)$ is calculated, based on the history of partial unloading. The modified reloading strain $\left(\varepsilon_{c r e}^{*}\right)$ is assumed to exist between the envelope unloading strain $\left(\varepsilon_{\text {cun }}\right)$ and the envelope reloading strain $\left(\varepsilon_{c r e}\right)$ for the complete unloading $(A \rightarrow B)$ and complete reloading $(B \rightarrow D)$ branches. Similarly, a modified intermediate stress $\left(f_{\text {cnew }}^{*}\right)$ is assumed to exist between the envelope unloading stress $\left(f_{\text {cun }}\right)$ and the intermediate stress $\left(f_{\text {cnew }}\right)$ for complete unloading and complete reloading branches. Linear interpolation is used for the determination of the $\varepsilon_{c r e}^{*}$ and $f_{\text {cnew }}^{*}$ :

$$
\begin{gathered}
f_{\text {cnew }}^{*}=f_{\text {cun }}-\Delta f_{c} \frac{\varepsilon_{c u n}-\varepsilon_{c r o}}{\varepsilon_{c u n}-\varepsilon_{c p l}} \\
E_{c n e w}^{*}=\frac{f_{c n e w}^{*}-f_{c r o}}{\mathcal{E}_{c u n}-\varepsilon_{c r o}}
\end{gathered}
$$


Varma, R.K., Barros, J.A.O., Sena-Cruz, J.M. (2009) Numerical model for CFRP confined concrete elements subject to monotonic and cyclic loadings, Composites Part B, 40(8): 766-775.

\begin{tabular}{|l|l|}
\hline$\varepsilon_{c r e}^{*}=\varepsilon_{c u n}+\Delta \varepsilon_{c} \frac{\varepsilon_{c u n}-\varepsilon_{c r o}}{\varepsilon_{a u n}-\varepsilon_{c p l}}$ & (24) \\
\hline$E_{c r e}^{*}=E_{c}\left(\varepsilon_{c r e}^{*}\right)$ & $(25)$ \\
\hline$f_{c r e}^{*}=f_{c}\left(\varepsilon_{c r e}^{*}\right)$ & $(26)$ \\
\hline
\end{tabular}

where $\left(\varepsilon_{c r o}, f_{c r o}\right)$ refers to the reversal point $B^{\prime}$ (see Fig. 5) located on the unloading curve, and $f_{c r e}^{*}$ and $E_{c r e}^{*}$ are calculated on the envelope curve. The transition curves are used to join $B^{\prime}$ to $C^{\prime}$, and $C^{\prime}$ to $D^{\prime}$ (see Table 5). In case of the loading path $A \rightarrow B \rightarrow E^{\prime} \rightarrow F^{\prime}$, a partial reloading $\left(B \rightarrow E^{\prime}\right.$ ) is followed by an unloading ( $E^{\prime} \rightarrow F^{\prime}$ ) branch. It should be noted that the plastic strain $\left(\varepsilon_{c p l}\right)$ and its corresponding plastic modulus $\left(E_{c p l}\right)$ are dependent only on the unloading strain of the envelope curve (Eqs. 12-14). From the experimental investigation it was found that for partial reloading ( $B \rightarrow C \rightarrow E^{\prime}$ ), the unloading branch $E^{\prime} \rightarrow F^{\prime}$ does not target the previous plastic strain (strain at point $B$ ). Hence, an imaginary unloading strain is assumed to exist between the previous envelope unloading strain ( $\varepsilon_{\text {cun }}$, corresponding to point $\mathrm{A}$ ) and the envelope reloading strain ( $\varepsilon_{\text {cre }}$, corresponding to point D). A new unloading strain, $\varepsilon_{\text {cun }}^{*}$, is defined on the envelope curve (see point I, Fig. 5) adopting a linear interpolation, which becomes the representative of the unloading strain (on envelope curve) for future responses, and is determined from:

$$
\varepsilon_{c u n}^{*}=\varepsilon_{c u n}+\left(\frac{\varepsilon_{c e^{\prime}}-\varepsilon_{c u n}}{\varepsilon_{c r e}-\varepsilon_{c p l}}\right)\left(\varepsilon_{c r e}-\varepsilon_{c u n}\right)
$$

where $\varepsilon_{c e^{\prime}}$ is the strain corresponding to $E^{\prime}$ on the reloading branch $\left(B \rightarrow E^{\prime}\right)$. The newly calculated unloading strain on the envelope curve ( $\varepsilon_{c u m}^{*}$, corresponding to point I) is used to calculate the new plastic strain $\varepsilon_{c p l}^{*}$ (point $F^{\prime}$ ) and the new plastic modulus $E_{c p l}^{*}$ using Eqs. 12-14. The transition curve is used to connect the points $E^{\prime}$ and $F^{\prime}$ (see Table 5), where $f_{c e^{\prime}}$ is the stress corresponding to $\varepsilon_{c e^{\prime}}$ on the reloading branch $\left(B \rightarrow E^{\prime}\right)$. Once the unloading branch $E^{\prime} \rightarrow F^{\prime}$ is initiated, the previous unloading strain $\left(\varepsilon_{\text {can }}\right)$ on the envelope curve is replaced by the newly calculated unloading strain on the envelope curve $\left(\varepsilon_{c u n}^{*}\right)$.

For a general loading path, illustrated by $A \rightarrow B^{\prime} \rightarrow E^{\prime \prime} \rightarrow F^{\prime \prime \prime} \rightarrow E^{\prime \prime \prime} \rightarrow J$, once first reloading starts, the modified envelope reloading strain ( $\varepsilon_{c r e}^{*}$, corresponding to point $D^{\prime}$ ) is calculated for the branch $B^{\prime} \rightarrow E^{\prime \prime}$ (same path as $B^{\prime} \rightarrow D^{\prime}$ ) using Eq. (24). The calculated reloading strain $\left(\varepsilon_{c r e}^{*}\right)$ on the envelope 
Varma, R.K., Barros, J.A.O., Sena-Cruz, J.M. (2009) Numerical model for CFRP confined concrete elements subject to monotonic and cyclic loadings, Composites Part B, 40(8): 766-775.

curve is used to decide the subsequent unloading paths $\left(E^{\prime \prime} \rightarrow F^{\prime \prime \prime}\right.$ or $E^{\prime \prime} \rightarrow F$ ), until a new reloading branch $\left(F^{\prime \prime \prime} \rightarrow E^{\prime \prime \prime}\right)$ is initiated. For the branch $E^{\prime \prime} \rightarrow F^{\prime \prime \prime}$, an unloading strain is calculated on the envelope curve using Eq. (27). In this Eq. the previously calculated modified reloading strain is used. A transition curve similar to $E^{\prime} \rightarrow F^{\prime}$ is used to simulate the branch that connects the points $E^{\prime \prime}$ and $F^{\prime \prime \prime}$. For the reloading branch $F^{\prime \prime \prime} \rightarrow E^{\prime \prime \prime}$, it should be noted that the intermediate point $E^{\prime \prime \prime}$ is calculated using Eq. (16), and the considered unloading stress and strain correspond to point $E^{\prime \prime}$. The branch $F^{\prime \prime \prime} \rightarrow E^{\prime \prime \prime}$ is similar to branch $B^{\prime} \rightarrow C^{\prime}$, except the calculation of the intermediate point. When the reloading branch $F^{\prime \prime \prime} \rightarrow E^{\prime \prime \prime}$ is extended up to the returning point $\mathrm{J}$ on envelope curve, point $\mathrm{J}$ is calculated using previously calculated (modified) unloading strain on the envelope curve (from Eq. (27)).

\section{Numerical Simulation}

\subsection{Introduction}

A fibre model with the cyclic constitutive laws for CFRP confined concrete described in the previous section was implemented into FEMIX computer program, which is based on the finite element method (FEM). The constitutive model developed by Chang and Mander [14] for the simulation of the cyclic behaviour of steel bars was also implemented into FEMIX. The fibre model is capable of analyzing the cyclic behaviour of three-dimensional RC frames, since the beams and columns are simulated with 3D Timoshenko finite elements. Each finite element is discretized in fibres along its longitudinal direction. A constitutive law is applied to every fibre at material level, according to the material characteristics and, a response is generated from each fibre. The collective response of the fibres produces the response at structural level.

\subsection{Model appraisal}

\subsubsection{Monotonic loading tests}

The cylindrical RC column elements tested by Barros and Ferreira [6] were numerically simulated using the values of the material properties included in Tables 1 and 2 (see also Fig. 1). The constitutive model of the steel bars was defined using the values included in Table 4. Along its longitudinal direction, a column is discretized with three FE of three nodes each, and two Gauss integration points per element were considered for the evaluation of the stiffness matrix and internal forces. In its longitudinal direction 
Varma, R.K., Barros, J.A.O., Sena-Cruz, J.M. (2009) Numerical model for CFRP confined concrete elements subject to monotonic and cyclic loadings, Composites Part B, 40(8): 766-775.

the three FE were discretized in 48 concrete fibres and 4 steel fibres. The cross section of a fibre was represented by eight nodded quadrilateral finite element. A $2 \times 2$ Gauss integration scheme was used for the calculation of the stiffness and internal forces at the level of fibre cross section. The steel bars were assumed to be perfectly bonded and embedded into the confined concrete. Fig. 10(a) and (b) shows that the implemented model was able to simulate, with high accuracy, the RC column elements subject to monotonic loading. The simulations terminated when the ultimate strain was reached.

\subsubsection{Cyclic loading tests}

The values of the model parameters used for the simulation of W60S6L3F8_c column are included in Tables 3, 4 and 5. This column was discretized in exactly the same manner as in the case of the simulations for the monotonic loading tests. Fig. 10(c) shows that the model used for the prediction of the hysteretic behaviour of CFRP confined RC columns is capable to simulate satisfactorily the deformational behaviour experimentally recorded. The simulation terminated after having been executed the preestablished number of cycles.

\subsubsection{Simulation of cyclic loading tests carried out by other researchers}

An independent monotonic series [14] and two cyclic series [9] were considered to appraise the model performance. Li et. al.[14] considered circular specimen of $300 \mathrm{~mm}$ high and $150 \mathrm{~mm}$ diameter. The data corresponding to the specimen is illustrated in Table 6. The cylindrical specimen was discretized in three $100 \mathrm{~mm}$ length of three nodded finite elements, each one was divided in 48 fibres in its longitudinal direction. For the calculation of the stiffness and internal forces, a $2 \times 2$ Gauss integration scheme was used for each fibre cross section, and 2 Gauss points were used for the finite element in its longitudinal direction. The compressive cyclic loading tests performed by Lam et al. [9] were also simulated by the developed constitutive model. The data available in the work of Lam et al. [9], included in Table 6, was used in the performed numerical simulations. The discretization and the integration scheme used in case of monotonic simulations were also adopted for the specimens subject to cyclic loading. The simulations were carried out up to the end of the measured experimental strain. The numerical and experimental stress-strain curves for monotonic and cyclic analysis are compared in Fig. 11, from which it can be concluded that the model is able to predict the response with a very good agreement. 
Varma, R.K., Barros, J.A.O., Sena-Cruz, J.M. (2009) Numerical model for CFRP confined concrete elements subject to monotonic and cyclic loadings, Composites Part B, 40(8): 766-775.

\section{Conclusions}

In the present work a constitutive model to simulate the monotonic and the cyclic behaviour of CFRP confined RC columns was developed. The concrete columns can be totally or partially wrapped with wet lay-up CFRP sheets. The carried out tests showed that the stress-strain curves of the monotonic loading tests can be regarded as the envelope of the stress-strain curves of the homologous cyclic loading tests. The monotonic stress-strain curve was composed of three branches. The first one having a linear relationship between strain and stress is governed by the characteristics of the concrete and conventional reinforcement. The third branch, with a smooth nonlinearity of the stress-strain relationship, is governed by the characteristics of the CFRP confinement arrangement. Finally, the second branch, which assures a continuous connection between the former and the later branches, has a pronounced nonlinearity and is affected by the properties of the concrete, conventional reinforcement and CFRP confinement arrangement. The model herein proposed is capable to predict the stress-strain response of any arbitrary loading path. In fact, the deterioration in terms of load carrying capacity and stiffness caused by the unloading/reloading cycles was simulated adequately, taking into account relevant data derived from the experimental tests. A stress-strain nonlinear relationship was used to simulate both the unloading and reloading branches, in agreement to the results observed in the experimental tests. The model was able to simulate, with high accuracy, the tests carried out by distinct researchers. 
Varma, R.K., Barros, J.A.O., Sena-Cruz, J.M. (2009) Numerical model for CFRP confined concrete elements subject to monotonic and cyclic loadings, Composites Part B, 40(8): 766-775.

\section{ACKNOWLEDGEMENTS}

The first author acknowledges the support provided by the grant within the ambit of the research program PABERPRO supported by Program POCI 2010 - IDEIA, Project n 13-05-04-FDR-00007, contract reference ADI/2007/V4.1/0049. The present work was also supported by Program PIDDAC, Project no. PTDC/ECM/74337/2006 by FCT. The authors wish to acknowledge the materials generously supplied by S\&P and Degussa Portugal.

\section{References}

[1] H. Saadatmanesh and M.R. Ehsani, M.W. Li,. Strength and ductility of concrete columns externally reinforced with fiber composite straps, ACI Struct. J. 91(July-Aug, 1994), pp.434-447.

[2] A. Nanni and N.M. Bradford, FRP jacketed concrete under uniaxial compression, Constr. and Build. Mat. 9(2) (1995), pp. 115-124.

[3] F. Picher, P. Rochette and P.Labossière, Confinement of concrete cylinders with CFRP, in: Proc. First Int. Conf. on Compos. Infrastructures, Tucson, Ariz,1996, pp. 829-841.

[4] M.R. Spolelstra and G. Monti, FRP-Confined Concrete Model, Journal of Composites for Construction, ASCE 3(3) (1999), pp. 144-150.

[5] L. Lam and J.G. Teng, Design-oriented stress-strain model for FRP-confined concrete, J. Construction and building materials, Elsevier vol. 17 (2003), pp. 471-489.

[6] J.A.O. Barros and D.R.S.M. Ferreira, Assessing the efficiency of CFRP discrete confinement systems for concrete column elements, Journal of Composites for Construction, ASCE 12(2) (2008), pp. 134148.

[7] X. Chen, FRP-wrapped concrete short column under uniaxial compression, Final report, National Diagnosis and Rehabilitation of Industrial Building Research Center, Beijing, China, 2001.

[8] Y. Shao, Z. Zhu and A. Mirmiran, Cyclic Modeling of FRP-Confined Concrete with Improved Ductility, Cement \& Concrete Composites 28(10) (2006), pp. 959-968.

[9] L. Lam, J.G. Teng, C.H. Cheung and Y. Xiao, FRP-confined concrete under cyclic axial compression, Cement \& Concrete Composites 28(10) (2006), pp. 949-958.

[10] D.R.S.M. Ferreira, CFRP-based confinement of circular concrete column elements - experimental and analytical research, PhD thesis, University of Minho, December 2007 (in Portuguese). 
Varma, R.K., Barros, J.A.O., Sena-Cruz, J.M. (2009) Numerical model for CFRP confined concrete elements subject to monotonic and cyclic loadings, Composites Part B, 40(8): 766-775.

[11] F. Seible, A. Burgueno, M.G. Abdallah and R. Nuismer, Advanced composites carbon shell system for bridge columns under seismic loads, in: Proceedings, National Seismic Conference on Bridges and Highways: San Diago, USA, 1995.

[12] J.B. Mander, M.J.N. Priestley and R. Park, Theoretical stress-strain model for confined concrete, J Struct Eng, ASCE 114(8) (1998), pp. $1804-1826$.

[13] M.H. Harajli, E. Hantouche and K. Soudki, Stress-strain model for fiber-reinforced polymer jacketed concrete columns, ACI Structural Journal 105(5) (2006), pp. 672-682.

[14] G.A. Chang and J.B. Mander, Seismic energy based fatigue damage analysis of bridge columns: Part I-Evaluation of seismic capacity, Tech. Report NCEER-94-0006, 1994.

[15] ISO TC 71/SC $6 \mathrm{~N}$, Non-conventional reinforcement of concrete-test methods-part 2: Fiber reinforced polymer (FRP) sheets, International standard, 2003.

[16] CEB-FIP, Model code, Thomas Telford, 1990.

[17] Y. Li, C. Lin, Y. Sung, A constitutive model for concrete confined with carbon fiber reinforced plastics, Mechanics of Materials, Volume 35, Issues 3-6, (2003), pp 603-619. 


\section{NOTATION}

\begin{tabular}{|c|c|c|}
\hline$A_{c, l}$ & $=$ & specimen longitudinal cross section \\
\hline$A_{f}$ & $=$ & cross section area of the confinement system \\
\hline$A_{g}$ & $=$ & area of specimen gross cross section \\
\hline$A_{s l}$ & $=$ & cross section area of the longitudinal bars \\
\hline$C F R P$ & $=$ & carbon fibre reinforced polymers \\
\hline$D$ & $=$ & diameter of the column cross section \\
\hline$d_{s t}$ & $=$ & diameter of the steel hoop \\
\hline$E_{c}$ & $=$ & Young modulus of Confined concrete \\
\hline$E_{c i}$ & $=$ & initial Young modulus of UPC \\
\hline$E_{\text {cnew }}$ & $=$ & tangent modulus at the new stress point \\
\hline$E_{c p l}$ & $=$ & tangent modulus when the stress is released \\
\hline$E_{c r e}$ & $=$ & tangent modulus at the returning point $\left(\varepsilon_{c r e}, f_{c r e}\right)$ \\
\hline$E_{c t}$ & $=$ & tangent modulus for concrete on compression envelope \\
\hline$E_{f}$ & $=$ & CFRP elasticity modulus \\
\hline$E_{s}$ & $=$ & elasticity modulus of the steel bars \\
\hline$E_{s h}$ & $=$ & tangent modulus at hardening strain for steel bars \\
\hline$f_{c}$ & $=$ & concrete compressive stress \\
\hline$f_{C P}$ & $=$ & concrete compressive stress at point $\mathrm{A}$ \\
\hline$f_{\text {cnew }}$ & $=$ & new value of stress corresponding to the unloading $\operatorname{strain}\left(\varepsilon_{\text {cun }}\right)$ \\
\hline$f_{c o, U P C}$ & $=$ & compressive strength of UPC \\
\hline$f_{c P}$ & $=$ & concrete compressive stress at end point of zone I \\
\hline$f_{c P}$ & $=$ & concrete compressive stress at starting point of zone III \\
\hline$f_{\text {cre }}$ & $=$ & stress on returning strain $\left(\varepsilon_{c r e}\right)$ \\
\hline$f_{c u}$ & $=$ & compressive strength of confined concrete \\
\hline$f_{\text {cun }, g}$ & $=$ & stress on FRP confined concrete at unloading $\operatorname{strain}\left(\varepsilon_{\text {cun }, g}\right)$ \\
\hline$f_{f l}$ & $=$ & effective lateral confining pressure exerted by CFRP \\
\hline$f_{l}$ & $=$ & effective lateral confining pressure \\
\hline$f_{s h}$ & $=$ & Steel stress at hardening \\
\hline$f_{s l}$ & $=$ & $\begin{array}{l}\text { effective lateral confining pressure exerted by ordinary steel } \\
\text { hoops }\end{array}$ \\
\hline$f_{s y}$ & $=$ & Steel tensile strength \\
\hline$f_{\text {syt }}$ & $=$ & Yield stress of steel hoop bar \\
\hline$f_{s u}$ & $=$ & Steel tensile stress \\
\hline$F_{l}$ & $=$ & diameter of steel hoops bar \\
\hline$H$ & $=$ & height of the specimen \\
\hline$k_{1}, k_{2}$ & $=$ & confinement effectiveness coefficients \\
\hline$L_{k}$ & $=$ & number of CFRP layers per each strip \\
\hline$s_{f}$ & $=$ & clear spacing between consecutive FRP strips \\
\hline$S_{j}$ & $=$ & number of strips along the specimen \\
\hline$S G$ & $=$ & Strain Gauge \\
\hline$s_{s}$ & $=$ & clear spacing between steel hoops \\
\hline$t_{f}$ & $=$ & thickness of the wet lay-up CFRP sheet \\
\hline$U P C$ & $=$ & unconfined plain concrete \\
\hline$W_{i}$ & $=$ & strip width \\
\hline$\alpha_{f e}, \alpha_{f v}$ & $=$ & $\begin{array}{l}\text { coefficients that account for the effectiveness of the FRP } \\
\text { systems in confining the concrete }\end{array}$ \\
\hline$\alpha_{s e}, \alpha_{s v}$ & $=$ & $\begin{array}{l}\text { coefficients that account for the effectiveness of the steel } \\
\text { hoops in confining the concrete }\end{array}$ \\
\hline$\beta$ & $=$ & $\begin{array}{l}\text { percent of } \varepsilon_{c o, U P C} \text { up to which UPC stress strain relation can be } \\
\text { assumed to be linear }\end{array}$ \\
\hline$\gamma$ & $=$ & percent of $\varepsilon_{c o, U P C}$ after to represent start of zone III \\
\hline
\end{tabular}


Varma, R.K., Barros, J.A.O., Sena-Cruz, J.M. (2009) Numerical model for CFRP confined concrete elements subject to monotonic and cyclic loadings, Composites Part B, 40(8): 766-775.

\begin{tabular}{|l|l|l|}
\hline$\varepsilon_{c}$ & $=$ & axial compressive strain \\
\hline$\varepsilon_{c o, U P C}$ & $=$ & $\begin{array}{l}\text { axial strain at compressive strength of unconfined plain } \\
\text { concrete }\left(f_{\text {co,UPC }}\right)\end{array}$ \\
\hline$\varepsilon_{c P}$ & $=$ & concrete axial compressive strain at end point of zone I \\
\hline$\varepsilon_{c p l}$ & $=$ & concrete plastic strain \\
\hline$\varepsilon_{c Q}$ & $=$ & concrete axial compressive strain at starting point of zone III \\
\hline$\varepsilon_{c r e}$ & $=$ & $\begin{array}{l}\text { strain on the FRP confined concrete envelope corresponding to } \\
\text { the return point }\end{array}$ \\
\hline$\varepsilon_{c u}$ & $=$ & concrete axial compressive strain at $f_{c u}$ \\
\hline$\varepsilon_{c u n, g}$ & $=$ & strain on FRP confined concrete at unloading (reversal) point \\
\hline$\varepsilon_{f}$ & $=$ & CFRP strain in the fibre direction \\
\hline$\varepsilon_{f m a x}$ & $=$ & maximum tensile strain in the CFRP fibre's direction \\
\hline$\varepsilon_{f u}$ & $=$ & CFRP ultimate strain \\
\hline$\varepsilon_{s h}$ & $=$ & Steel hardening strain \\
\hline$\varepsilon_{s u}$ & $=$ & Steel ultimate strain \\
\hline$\rho_{f}$ & $=$ & CFRP volumetric ratio \\
\hline$\rho_{s t}$ & $=$ & volumetric ratio of steel hoops \\
\hline
\end{tabular}


Varma, R.K., Barros, J.A.O., Sena-Cruz, J.M. (2009) Numerical model for CFRP confined concrete elements subject to monotonic and cyclic loadings, Composites Part B, 40(8): 766-775.

\section{TABLE CAPTIONS}

Table 1 - G1 group of tests $\left(f_{c o, U P C}=13.87 \mathrm{MPa}, \boldsymbol{\varepsilon}_{c o, U P C}=0.27 \%\right)$

Table 2 - G2 group of tests $\left(f_{c o, U P C}=30.31 \mathrm{MPa}, \boldsymbol{\varepsilon}_{c o, U P C}=0.31 \%\right)$

Table 3 - G3 group of tests $\left(f_{c o, U P C}=26.47 \mathrm{MPa}, \boldsymbol{\varepsilon}_{c o, U P C}=0.30 \%\right)$

Table 4 - Data used in the numerical analysis to simulate the behaviour of the steel bars, obtained from the experimental characterization.

Table 5 - Parameters for the transition curves

Table 6 - Experimental data used in the numerical simulation 
Varma, R.K., Barros, J.A.O., Sena-Cruz, J.M. (2009) Numerical model for CFRP confined concrete elements subject to monotonic and cyclic loadings, Composites Part B, 40(8): 766-775.

Table 1 - G1 group of tests $\left(f_{c o, U P C}=13.87 \mathrm{MPa}, \varepsilon_{c o, U P C}=0.27 \%\right)$

\begin{tabular}{|c|c|c|c|c|}
\hline Specimen name & $\mathrm{t}_{\mathrm{f}}[\mathrm{mm}]$ & $\rho_{\mathrm{f}}$ & $\varepsilon_{c u} / \mathcal{E}_{c o, U P C}$ & $f_{c u} / f_{c o, U P C}$ \\
\hline "W45S6L3F8_m & 0.113 & 0.0031 & 5.82 & 1.99 \\
\hline W45S6L5F8_m & 0.113 & 0.0051 & 9.09 & 2.56 \\
\hline W60S6L3F8_m & 0.113 & 0.0041 & 6.36 & 2.48 \\
\hline W60S6L5F8_m & 0.113 & 0.0068 & 10.30 & 3.14 \\
\hline W600S1L3F8_m & 0.113 & 0.0068 & 9.39 & 3.45 \\
\hline W600S1L5F8_m & 0.113 & 0.0113 & 12.12 & 4.47 \\
\hline W45S6L3F8_m & 0.176 & 0.0048 & 10.00 & 2.60 \\
\hline W45S6L5F8_m & 0.176 & 0.0079 & 13.94 & 3.30 \\
\hline W60S6L3F8_m & 0.176 & 0.0063 & 11.18 & 3.33 \\
\hline W60S6L5F8_m & 0.176 & 0.0106 & 17.58 & 4.68 \\
\hline W600S1L3F8_m & 0.176 & 0.0106 & 10.00 & 3.76 \\
\hline W600S1L5F8_m & 0.176 & 0.0176 & 14.85 & 5.42 \\
\hline W45S5L3F10_m & 0.113 & 0.0025 & 6.09 & 1.95 \\
\hline W45S5L5F10_mb & 0.113 & 0.0042 & 9.60 & 2.37 \\
\hline W60S5L3F10_m & 0.113 & 0.0034 & 7.91 & 2.37 \\
\hline W60S5L5F10_m & 0.113 & 0.0057 & 12.27 & 3.16 \\
\hline W600S1L3F10_m & 0.113 & 0.0068 & 8.98 & 3.38 \\
\hline W600S1L5F10_m & 0.113 & 0.0113 & 10.41 & 4.06 \\
\hline W45S5L3F10_m & 0.176 & 0.0040 & 8.60 & 2.23 \\
\hline W45S5L5F10_m & 0.176 & 0.0066 & 12.12 & 2.76 \\
\hline W60S5L3F10_m & 0.176 & 0.0053 & 9.78 & 2.66 \\
\hline W60S5L5F10_m & 0.176 & 0.0088 & 12.22 & 3.34 \\
\hline W600S1L3F10_m & 0.176 & 0.0106 & 12.87 & 4.52 \\
\hline W600S1L5F10_m & 0.176 & 0.0176 & 14.55 & 5.42 \\
\hline
\end{tabular}

${ }^{\mathrm{b}}$ Used for numerical simulation 
Varma, R.K., Barros, J.A.O., Sena-Cruz, J.M. (2009) Numerical model for CFRP confined concrete elements subject to monotonic and cyclic loadings, Composites Part B, 40(8): 766-775.

Table 2 - G2 group of tests $\left(f_{c o, U P C}=30.31 \mathrm{MPa}, \varepsilon_{c o, U P C}=0.31 \%\right)$

\begin{tabular}{|c|c|c|c|c|}
\hline Specimen name & $\mathrm{t}_{\mathrm{f}}[\mathrm{mm}]$ & $\rho_{\mathrm{f}}$ & $\varepsilon_{c u} / \varepsilon_{c o, U P C}$ & $f_{c u} / f_{c o, U P C}$ \\
\hline "W45S6L3F8_m & 0.113 & 0.0031 & 3.07 & 1.48 \\
\hline W45S6L5F8_m & 0.113 & 0.0051 & 4.63 & 1.83 \\
\hline W60S6L3F8_m & 0.113 & 0.0041 & 4.57 & 1.79 \\
\hline W60S6L5F8_m & 0.113 & 0.0068 & 5.97 & 2.21 \\
\hline W600S1L3F8_mb & 0.113 & 0.0068 & 6.03 & 2.35 \\
\hline W600S1L5F8_m & 0.113 & 0.0113 & 4.67 & 2.36 \\
\hline W45S6L3F8_m & 0.176 & 0.0048 & 4.40 & 1.74 \\
\hline W45S6L5F8_m & 0.176 & 0.0079 & 6.17 & 2.00 \\
\hline W60S6L3F8_m & 0.176 & 0.0063 & 6.17 & 2.10 \\
\hline W60S6L5F8_m & 0.176 & 0.0106 & 7.50 & 2.57 \\
\hline W600S1L3F8_m & 0.176 & 0.0106 & 5.60 & 3.09 \\
\hline W600S1L5F8_m & 0.176 & 0.0176 & 4.03 & 3.83 \\
\hline W45S5L3F10_m & 0.113 & 0.0025 & 2.28 & 1.43 \\
\hline W45S5L5F10_m & 0.113 & 0.0042 & 2.81 & 1.62 \\
\hline W60S5L3F10_m & 0.113 & 0.0034 & 2.68 & 1.58 \\
\hline W60S5L5F10_m & 0.113 & 0.0057 & 3.50 & 1.69 \\
\hline W600S1L3F10_m & 0.113 & 0.0068 & 4.17 & 2.36 \\
\hline W600S1L5F10_m & 0.113 & 0.0113 & 2.66 & 3.31 \\
\hline W45S5L3F10_m & 0.176 & 0.0040 & 3.18 & 1.52 \\
\hline W45S5L5F10_m & 0.176 & 0.0066 & 4.13 & 1.79 \\
\hline W60S5L3F10_m & 0.176 & 0.0053 & 3.50 & 1.85 \\
\hline W60S5L5F10_m & 0.176 & 0.0088 & 5.03 & 2.12 \\
\hline W600S1L3F10_m & 0.176 & 0.0106 & 2.91 & 3.17 \\
\hline W600S1L5F10_m & 0.176 & 0.0176 & 3.05 & 3.67 \\
\hline
\end{tabular}

${ }^{\mathrm{b}}$ Used for numerical simulation 
Varma, R.K., Barros, J.A.O., Sena-Cruz, J.M. (2009) Numerical model for CFRP confined concrete elements subject to monotonic and cyclic loadings, Composites Part B, 40(8): 766-775.

Table 3 - G3 group of tests $\left(f_{c o, U P C}=26.47 \mathrm{MPa}, \varepsilon_{c o, U P C}=0.30 \%\right)$

\begin{tabular}{|c|c|c|c|c||}
\hline Specimen name & $\mathrm{t}_{\mathrm{f}}[\mathrm{mm}]$ & $\rho_{\mathrm{f}}$ & $\mathcal{E}_{c u} / \varepsilon_{c o, U P C}$ & $f_{c u} / f_{c o, U P C}$ \\
\hline \hline W45S6L3F8_m ${ }^{\mathrm{a}}$ & 0.113 & 0.0031 & 6.00 & 1.49 \\
\hline W45S6L5F8_m & 0.113 & 0.0051 & 8.00 & 1.97 \\
\hline W60S6L3F8_m & 0.113 & 0.0041 & 6.33 & 1.89 \\
\hline W60S6L5F8_m ${ }^{\mathrm{a}}$ & 0.113 & 0.0068 & 6.67 & 2.42 \\
\hline W600S1L3F8_m & 0.113 & 0.0068 & 8.33 & 2.11 \\
\hline W45S6L3F8_c & 0.113 & 0.0031 & 5.00 & 1.62 \\
\hline W45S6L5F8_c & 0.113 & 0.0051 & 8.33 & 1.85 \\
\hline W60S6L3F8_c & 0.113 & 0.0041 & 6.33 & 1.78 \\
\hline W60S6L5F8_c & 0.113 & 0.0068 & 9.33 & 2.03 \\
\hline W600S1L3F8_c & 0.113 & 0.0068 & 4.67 & 2.69 \\
\hline \hline
\end{tabular}

${ }^{a}$ Used in Fig. 2 for representation

${ }^{\mathrm{b}}$ Used for numerical simulation 
Varma, R.K., Barros, J.A.O., Sena-Cruz, J.M. (2009) Numerical model for CFRP confined concrete elements subject to monotonic and cyclic loadings, Composites Part B, 40(8): 766-775.

Table 4 - Data used in the numerical analysis to simulate the behaviour of the steel bars, obtained from the experimental characterization.

\begin{tabular}{|c|c|c|c|c|c|c|c|}
\hline $\begin{array}{c}\text { Diameter } \\
{[\mathrm{mm}]}\end{array}$ & $\begin{array}{c}E_{s} \\
{\left[\mathrm{~N} / \mathrm{mm}^{2}\right]}\end{array}$ & $\begin{array}{c}f_{s y} \\
{\left[\mathrm{~N} / \mathrm{mm}^{2}\right]}\end{array}$ & $\begin{array}{c}\varepsilon_{s h} \\
{[\mathrm{~mm} / \mathrm{mm}]}\end{array}$ & $\begin{array}{c}f_{s h} \\
{\left[\mathrm{~N} / \mathrm{mm}^{2}\right]}\end{array}$ & $\begin{array}{c}\varepsilon_{s u} \\
{[\mathrm{~mm} / \mathrm{mm}]}\end{array}$ & $\begin{array}{c}f_{s u} \\
{\left[\mathrm{~N} / \mathrm{mm}^{2}\right]}\end{array}$ & $\begin{array}{c}E_{s h} \\
{\left[\mathrm{~N} / \mathrm{mm}^{2}\right]}\end{array}$ \\
\hline \hline 6 & 212200.0 & 468.3 & - & 468.3 & 0.08 & 616.2 & - \\
\hline \hline 8 & 199800.0 & 517.2 & 0.0075 & 517.0 & 0.11 & 607.9 & 6400.0 \\
\hline 10 & 200000.0 & 421.2 & 0.0075 & 421.2 & 0.14 & 539.3 & 6400.0 \\
\hline
\end{tabular}


Varma, R.K., Barros, J.A.O., Sena-Cruz, J.M. (2009) Numerical model for CFRP confined concrete elements subject to monotonic and cyclic loadings, Composites Part B, 40(8): 766-775.

Table 5 - Parameters for the transition curves

\begin{tabular}{|c|c|c|c|c|c|c|c||}
\hline \hline Parameters & $\begin{array}{c}\text { Zone II } \\
P \rightarrow Q\end{array}$ & $A \rightarrow B$ & $B \rightarrow C$ & $C \rightarrow D$ & $B^{\prime} \rightarrow C^{\prime}$ & $C^{\prime} \rightarrow D^{\prime}$ & $E^{\prime} \rightarrow F^{\prime}$ \\
\hline \hline$\varepsilon_{c a}$ & $\varepsilon_{c P}$ & $\varepsilon_{c u n}$ & $\varepsilon_{c p l}$ & $\varepsilon_{c u n}$ & $\varepsilon_{c r o}$ & $\varepsilon_{c u n}$ & $\varepsilon_{c e^{\prime}}$ \\
\hline$f_{c a}$ & $f_{c P}$ & $f_{c u n}$ & 0 & $f_{c n e w}$ & $f_{c r o}$ & $f_{c n e w}^{*}$ & $f_{c e^{\prime}}$ \\
\hline$E_{c a}$ & $E_{c P}$ & $E_{c i}$ & $E_{c i}$ & $E_{c n e w}$ & $E_{c i}$ & $E_{c n e w}^{*}$ & $E_{c i}$ \\
\hline$\varepsilon_{c b}$ & $\varepsilon_{c Q}$ & $\varepsilon_{c p l}$ & $\varepsilon_{c u n}$ & $\varepsilon_{c r e}$ & $\varepsilon_{c u n}$ & $\varepsilon_{c r e}^{*}$ & $\varepsilon_{c p l}^{*}$ \\
\hline$f_{c b}$ & $f_{c Q}$ & 0 & $f_{c n e w}$ & $f_{c r e}$ & $f_{c n e w}^{*}$ & $f_{c r e}^{*}$ & 0 \\
\hline$E_{c b}$ & $E_{c Q}$ & $E_{c p l}$ & $E_{c n e w}$ & $E_{c r e}$ & $E_{c n e w}^{*}$ & $E_{c r e}^{*}$ & $E_{c p l}^{*}$ \\
\hline
\end{tabular}


Varma, R.K., Barros, J.A.O., Sena-Cruz, J.M. (2009) Numerical model for CFRP confined concrete elements subject to monotonic and cyclic loadings, Composites Part B, 40(8): 766-775.

Table 6 - Experimental data used in the numerical simulation

\begin{tabular}{|l|c|c|c|c|c|c|c|c|c|c||}
\hline Specimen name & $\begin{array}{c}\mathrm{W} \\
{[\mathrm{mm}]}\end{array}$ & $\begin{array}{c}\mathrm{L} \\
{[\mathrm{mm}]}\end{array}$ & $\begin{array}{c}\mathrm{S} \\
{[\mathrm{mm}]}\end{array}$ & $\begin{array}{c}\mathrm{t}_{\mathrm{f}} \\
{[\mathrm{mm}]}\end{array}$ & $\begin{array}{c}\mathrm{D} \\
{[\mathrm{mm}]}\end{array}$ & $\begin{array}{c}\mathrm{H} \\
{[\mathrm{mm}]}\end{array}$ & $\begin{array}{c}\mathrm{E}_{\mathrm{f}} \\
{[\mathrm{GPa}]}\end{array}$ & $\rho_{\mathrm{f}}$ & $\begin{array}{c}\mathrm{f}_{\mathrm{co}, \mathrm{UPC}} \\
{[\mathrm{MPa}]}\end{array}$ & $\begin{array}{c}\varepsilon_{\mathrm{co}, \mathrm{UPC}} \\
{[\mathrm{mm} / \mathrm{mm}]}\end{array}$ \\
\hline \hline Li et al. & 300 & 1 & 1 & 0.138 & 150 & 300 & 232 & 0.0073 & 17.2 & 0.00200 \\
\hline Lam et al. (A) & 305 & 1 & 1 & 0.165 & 152 & 305 & 250 & 0.0043 & 41.1 & 0.00256 \\
\hline Lam et al. (B) & 305 & 2 & 1 & 0.165 & 152 & 305 & 250 & 0.0087 & 38.9 & 0.00250 \\
\hline
\end{tabular}


Varma, R.K., Barros, J.A.O., Sena-Cruz, J.M. (2009) Numerical model for CFRP confined concrete elements subject to monotonic and cyclic loadings, Composites Part B, 40(8): 766-775.

\section{FIGURE CAPTIONS}

Fig. 1 - Confinement arrangements of the tested specimens and corresponding cross-section. Note: all dimensions are in millimetres.

Fig. 2 - (a) $f_{c u} / f_{c o, U P C}$ vs. $\rho_{\mathrm{f}}$ and (b) $\varepsilon_{c u} / \varepsilon_{c o, U P C}$ vs. $\rho_{\mathrm{f}}$ for the specimens with longitudinal reinforcement of $8 \mathrm{~mm}$ diameter (Table 1).

Fig. 3 - Cyclic and monotonic stress-strain curves for (a) W45S6L3F8_m/c and, (b) W60S6L5F8_m/c specimens.

Fig. 4 - Schematic illustration of the FRP-confined concrete envelope curve.

Fig. 5 - Schematic illustration of the FRP-confined concrete hysteretic model

Fig. 6 - Variation of $\mathrm{k}_{1}$ with $f_{l} / f_{c o, U P C}$ for a) $\mathrm{G} 1\left(f_{c o, U P C}=13.87 \mathrm{MPa}\right)$ and b) G2 $\left(f_{c o, U P C}=30.31 \mathrm{MPa}\right)$ group of tests. Note: all the square points are obtained from the experimental results.

Fig. 7 - Variation of $\mathrm{k}_{2}$ with $\varepsilon_{l}$ for a) $\mathrm{G} 1\left(f_{c o, U P C}=13.87 \mathrm{MPa}\right)$ and b) G2 $\left(f_{c o, U P C}=30.31 \mathrm{MPa}\right)$ group of tests. Note: all the square points are obtained from the experimental results.

Fig. 8 - Variation of normalized secant with normalized axial strain

Fig. 9 - Variation of $\Delta f_{c} / f_{\text {cun }, g}$ with $\varepsilon_{c u n, g} / \varepsilon_{c u}$

Fig. 10 - Numerical and experimental results for specimens from groups: (a) G1, (b) G2 and (c) G3.

Fig. 11 - Numerical and experimental results for (a) Li et. al., (b) Lam et. al. (A), and (c) Lam et al. (B). 

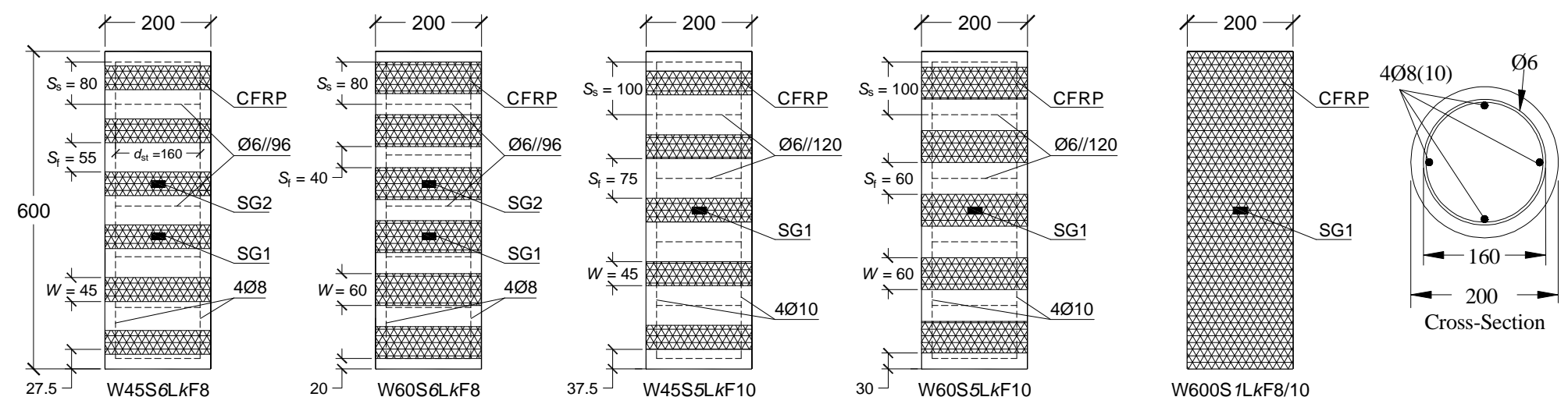

Fig. 1 - Confinement arrangements of the tested specimens and corresponding cross-section. Note: all dimensions are in millimetres. 

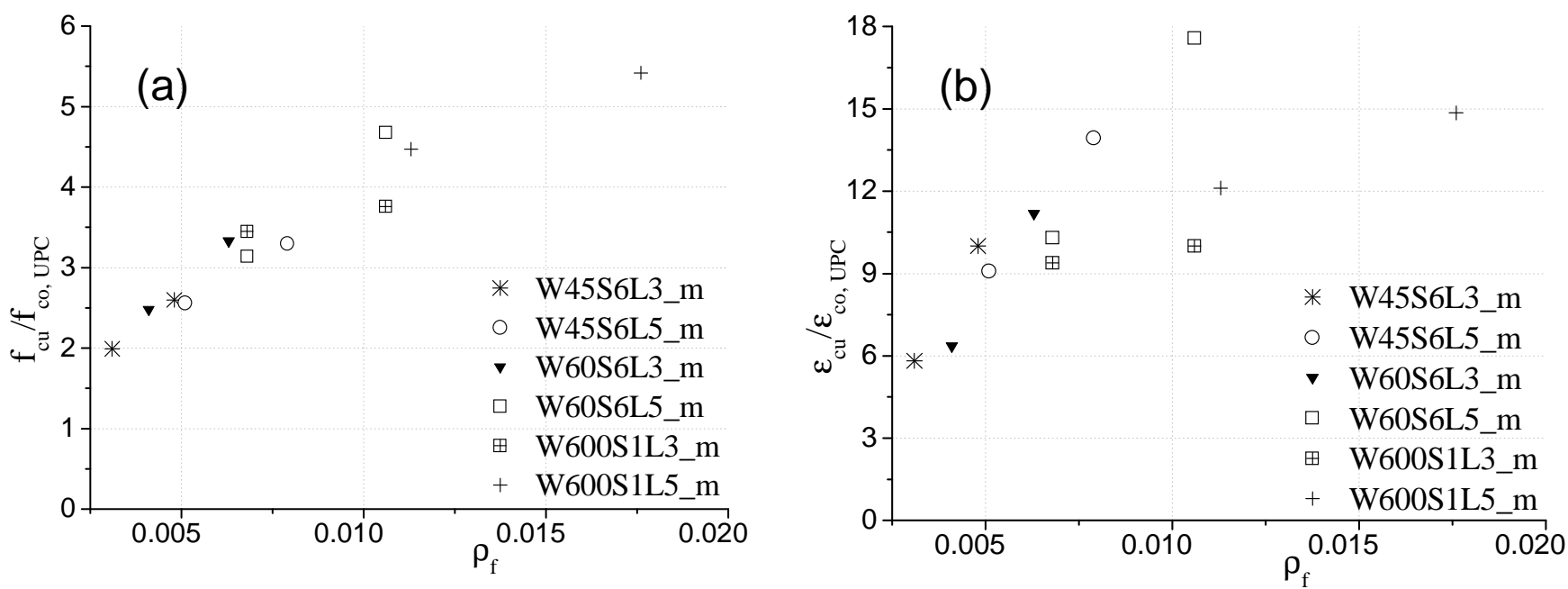

Fig. 2- (a) $f_{c u} / f_{c o, U P C}$ vs. $\rho_{\mathrm{f}}$ and (b) $\varepsilon_{c u} / \varepsilon_{c o, U P C}$ vs. $\rho_{\mathrm{f}}$ for the specimens with longitudinal reinforcement of 8 mm diameter (Table 1). 

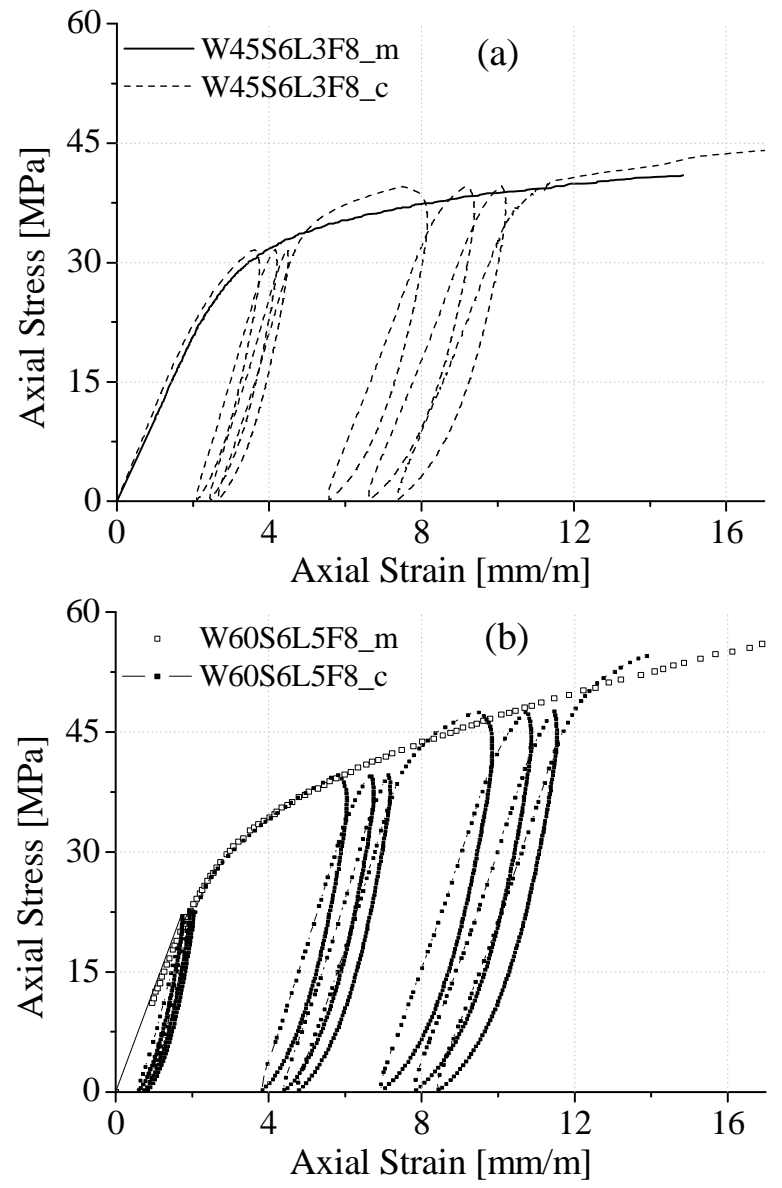

Fig. 3 - Cyclic and monotonic stress-strain curves for (a)W45S6L3F8_m/c and (b)W60S6L5F8_m/c specimens. 


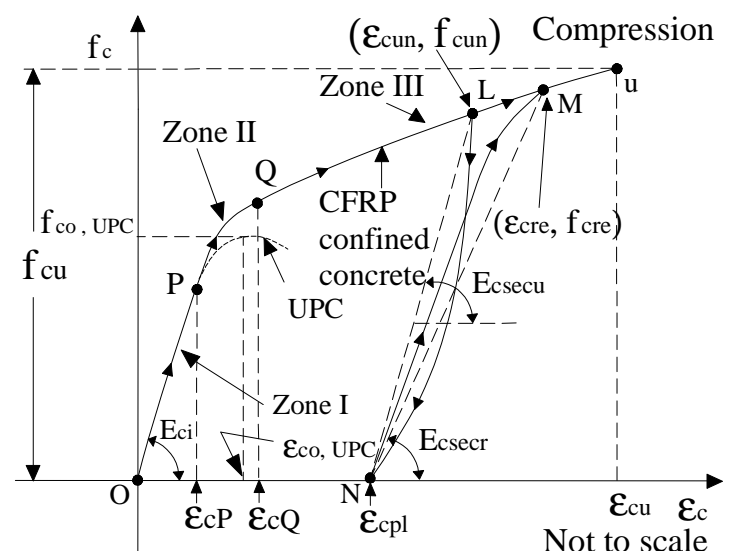

Fig. 4 - Schematic illustration of the FRP-confined concrete envelope curve 


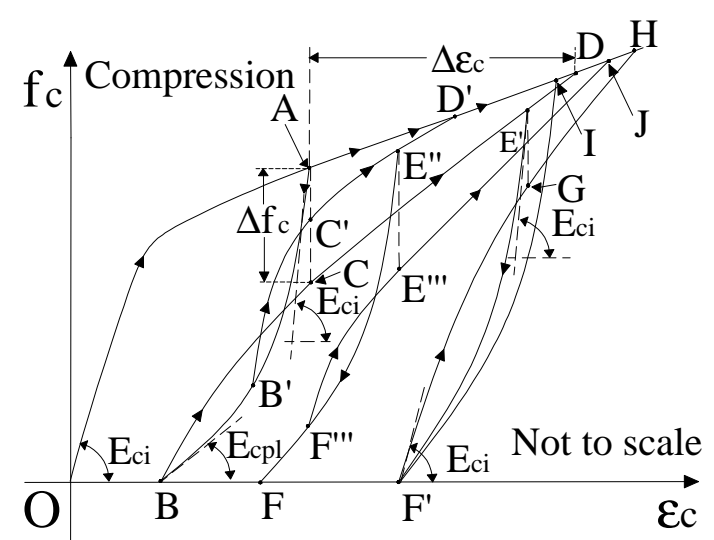

Fig. 5 - Schematic illustration of the FRP-confined concrete hysteretic model. 

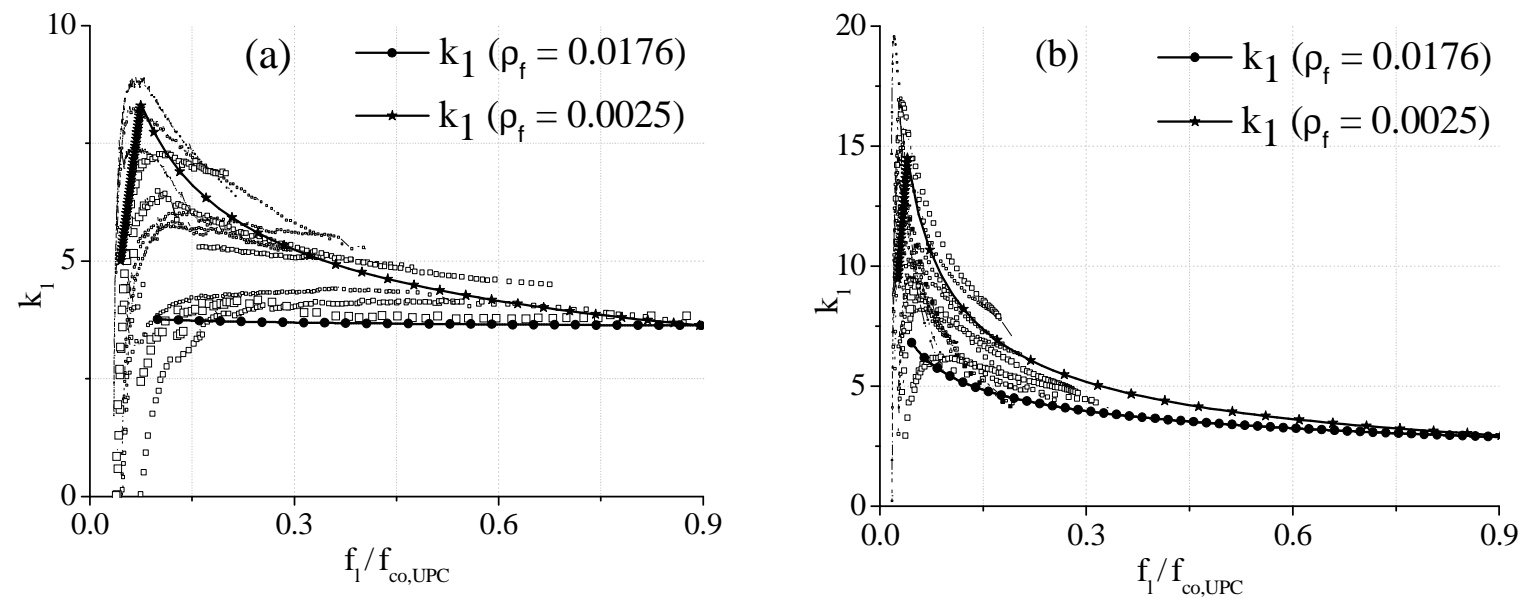

Fig. 6 - Variation of $\mathrm{k}_{1}$ with $f_{l} / f_{\text {co.UPC }}$ for (a) G1 and (b) G2 group of tests. Note: all the square points are obtained from the experimental results. 
Varma, R.K., Barros, J.A.O., Sena-Cruz, J.M. (2009) Numerical model for CFRP confined concrete elements subject to monotonic and cyclic loadings, Composites Part B, 40(8): 766-775.
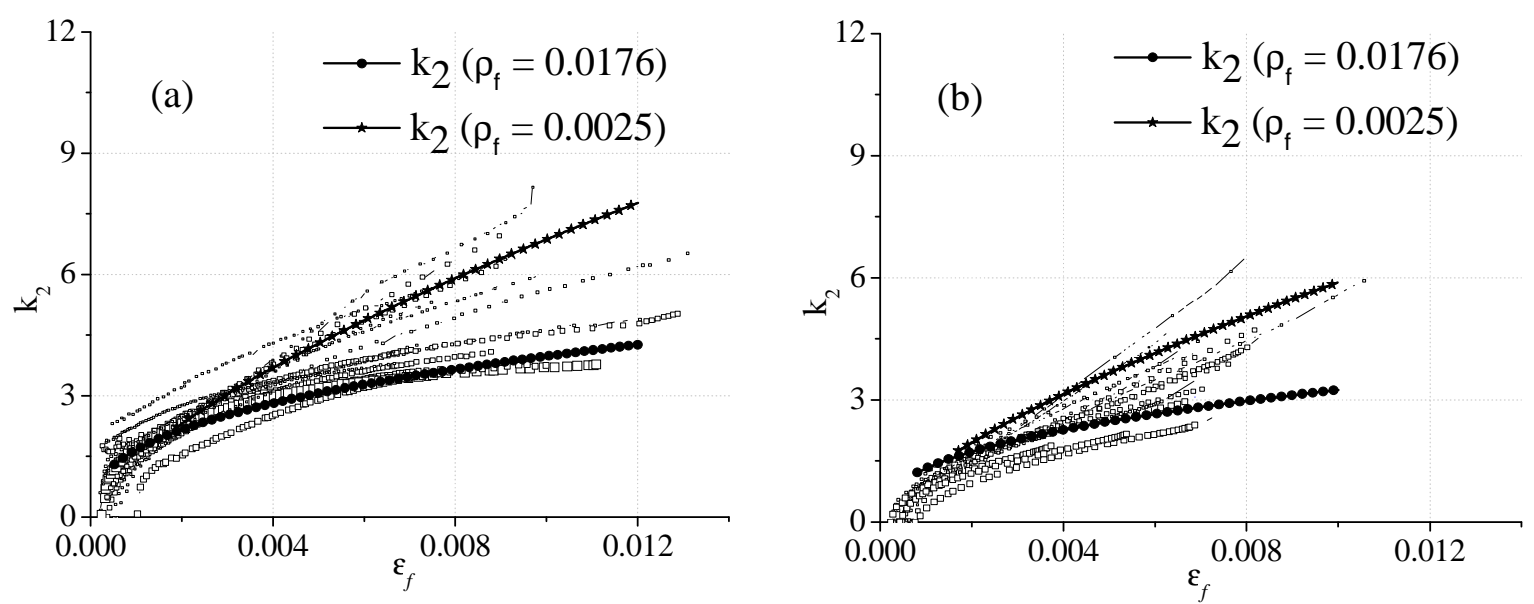

Fig. 7 - Variation of $\mathrm{k}_{2}$ with $\varepsilon_{l}$ for (a) G1 and (b) G2 group of tests. . Note: all the square points are obtained from the experimental results. 
Varma, R.K., Barros, J.A.O., Sena-Cruz, J.M. (2009) Numerical model for CFRP confined concrete elements subject to monotonic and cyclic loadings, Composites Part B, 40(8): 766-775.

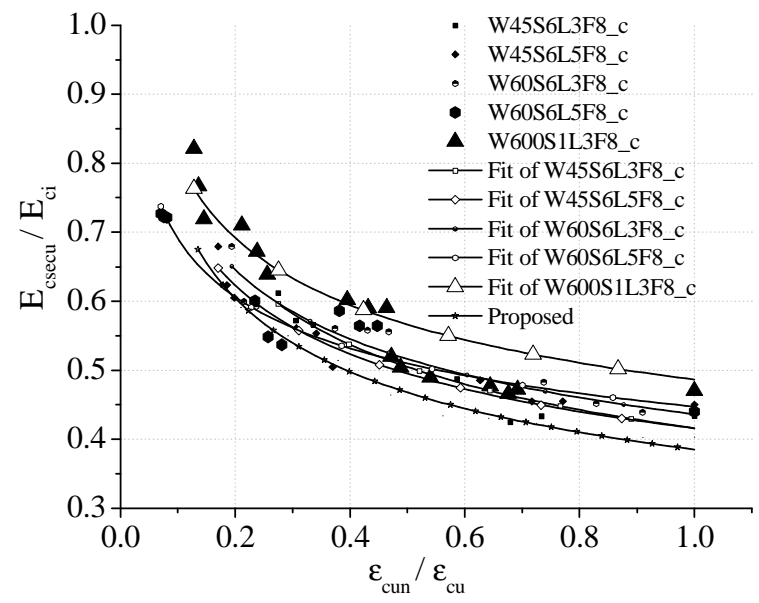

Fig. 8 - Variation of normalized secant with normalized axial strain. 
Varma, R.K., Barros, J.A.O., Sena-Cruz, J.M. (2009) Numerical model for CFRP confined concrete elements subject to monotonic and cyclic loadings, Composites Part B, 40(8): 766-775.

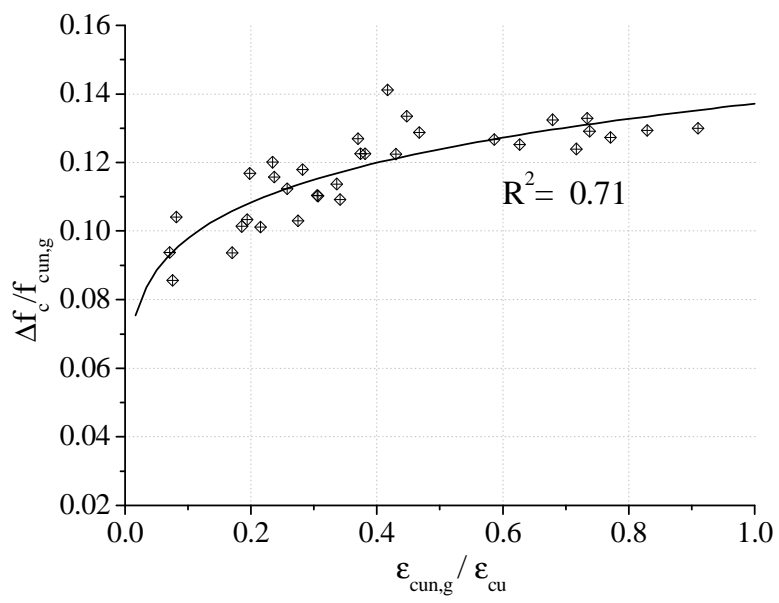

Fig. 9 - Variation of $\Delta f_{c} / f_{c u n, g}$ with $\varepsilon_{c u n, g} / \varepsilon_{c u}$. 

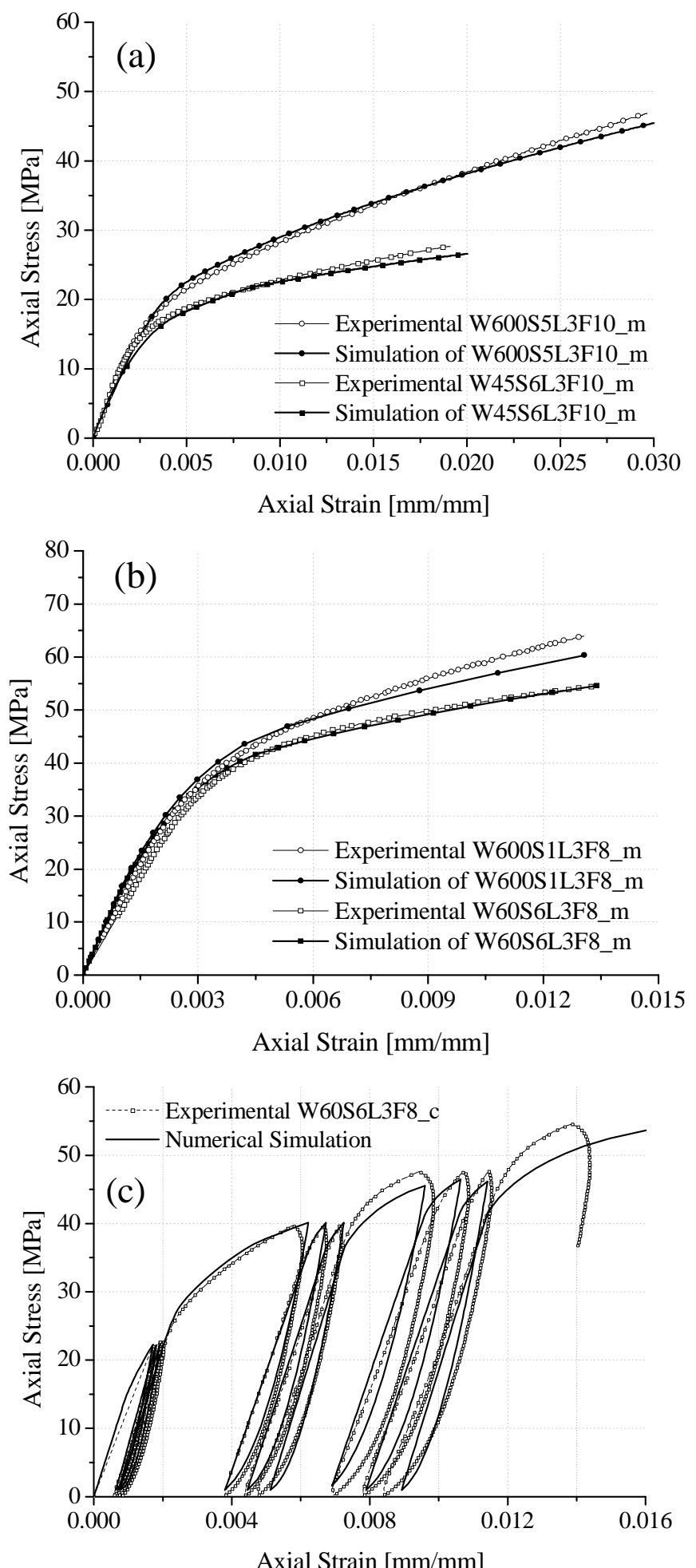

Fig. 10 - Numerical and experimental results for specimens from groups: (a) G1, (b) G2 and (c) G3. 
Varma, R.K., Barros, J.A.O., Sena-Cruz, J.M. (2009) Numerical model for CFRP confined concrete elements subject to monotonic and cyclic loadings, Composites Part B, 40(8): 766-775.

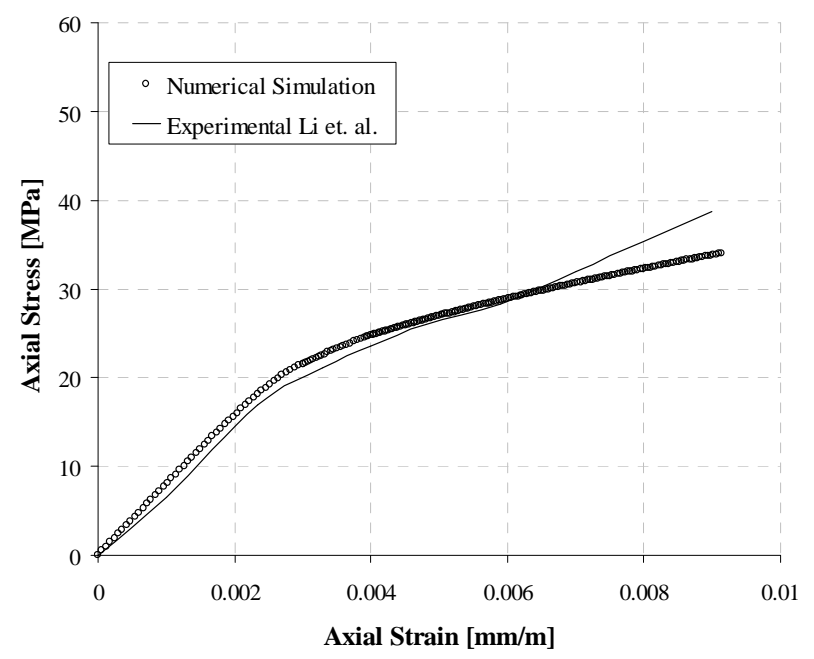

(a)

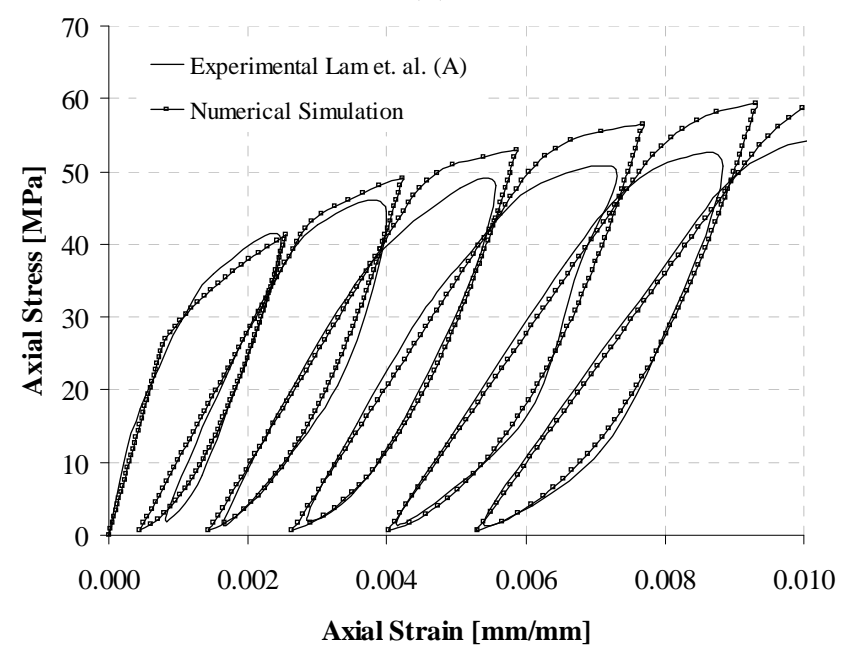

(b)

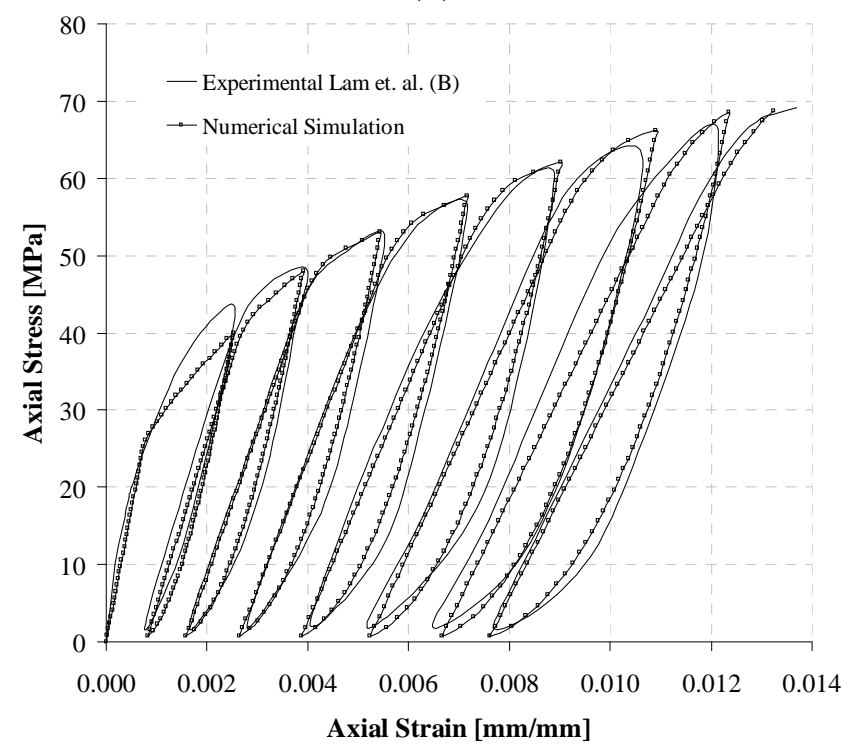

(c)

Fig. 11 - Numerical and experimental results for (a) Li et. al (b) Lam et. al. (A), and (c) Lam et al. (B). 